\title{
The Nucleation and Growth of $\eta$ Phase in Nickel-based Superalloy during Long-term
}

\section{Thermal Exposure}

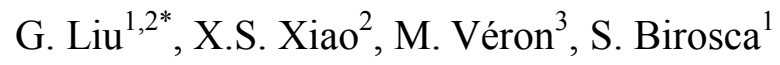 \\ ${ }^{1}$ Materials Research Centre, College of Engineering, Swansea University, Bay Campus, \\ Swansea SA1 8EN, UK. \\ ${ }^{2}$ Laboratory for Microstructure, Institute of Materials, Shanghai University, Shanghai \\ 200072, China \\ ${ }^{3}$ SIMAP Laboratory, CNRS-Grenoble INP, BP 46101 rue de la Physique, 38402 Saint \\ Martin d'Hères, France
}

\begin{abstract}
The microstructure degradation and subsequent phases transformation in Waspaloy nickelbased superalloy during thermal exposure at $780{ }^{\circ} \mathrm{C}$ for $10,000 \mathrm{~h}$ are investigated. Two paths of $\eta$ phase formation in the centre of extra-large $\gamma^{\prime}\left(\right.$ EL- $\left.\gamma^{\prime}\right)$ following the formation of EL- $\gamma^{\prime}$ were observed: (i) $\eta$ phase directly precipitated within EL- $\gamma^{\prime}$ when the coalescence of $\gamma^{\prime}$ reached a critical stage; (ii) $\eta$ phase precipitated at the interface of small size MC carbide and EL- $\gamma$ ', with both MC and $\eta$ embedded inside EL- $\gamma^{\prime}$. The phase transformation process including the formation of EL- $\gamma$ ' were experimentally observed and the formation sequences were schematically suggested. Two criteria of $\eta$ formation and growth within EL- $\gamma^{\prime}$ were established: (i) stacking faults formation in the nucleation site and (ii) sufficient atom diffusion during nuclei growth. The study of kinetics of $\eta$ formation through two different paths revealed the critical role of the small size carbides in promoting $\eta$ nucleation and
\end{abstract}


growth. It is concluded that $\eta$ formation may be suppressed by controlling the size and density of MC carbides during materials processing.

Key words: Nickel-based superalloy; $\eta$ phase; MC-carbide; Phase transformation, Waspaloy.

\section{Introduction}

To improve engine efficiency and reduce $\mathrm{CO}_{2}$ emissions in power generation industry, higher temperature and thus higher strength and stability of heat resistant materials are needed for advanced ultra-supercritical (A-USC) boilers [1]. Nickel-based superalloy are widely considered to be promising candidates [2] to replace the conventional high strength steels [3] due to their good combination of high strength and corrosion resistance at high temperatures. One of potential candidate is Waspaloy, a wrought nickel-based superalloy which has been widely used in turbine disk and turbine blade application [4]. Most of the strength of Waspaloy derives from fine strengthening particles, $\gamma^{\prime}-\mathrm{Ni}_{3}(\mathrm{Al}, \mathrm{Ti})\left(\mathrm{L}_{2}\right.$-ordered, $\left.\mathrm{FCC}\right)$, coherently precipitated within $\gamma$ matrix. However, Waspaloy is susceptible to precipitate $\eta$ $\mathrm{Ni}_{3} \mathrm{Ti}$ phase $\left(\mathrm{HCP}, \mathrm{D0}_{24}\right)$ at intermediate or high temperature during long-term exposure, especially under external stress. This is mainly due to the relatively higher $\mathrm{Ti} / \mathrm{Al}$ ratio composition in Waspaloy, as it is widely established that high Ti content or Ti/Al ratio would promote the formation of $\eta$ phase $[5,6]$. The $\eta$ phase is generally regarded as a detrimental phase, exerting negative effect on tensile [7] and creep-rupture properties [5, 6], although Shingledecker and Pharr [8] pointed out that the exact amount of $\eta$ phase has to be taken into account when evaluating their effects on creep property. The detrimental effect of $\eta$ phase is largely attributed to its formation and growth at the expense of the strengthening phase $\gamma^{\prime}$ [911]. Nonetheless, Evans et al. [10] suggested it might be beneficial to promote $\eta$ phase formation only on the grain boundaries to avoid grain boundary sliding during creep. 
Moreover, Smith et al. [12] recently reported a beneficial effect of shear-induced phase transformation (from $\gamma^{\prime}$ to $\eta$ ) on creep property by slightly increasing the content of $\eta$ forming elements.

It is widely accepted that $\gamma^{\prime}-\mathrm{Ni}_{3}(\mathrm{Al}, \mathrm{Ti})$ is metastable compared to $\eta$ phase at relatively high temperatures. This is further confirmed through thermodynamic calculations where it was found that $\gamma^{\prime}$ was not an equilibrium phase above $750{ }^{\circ} \mathrm{C}$ and would transform to the $\eta$ phase in some superalloys [9]. However, theoretical evaluation of the phase stability of $\gamma^{\prime}$ and $\eta[13$, 14] have revealed a very close formation enthalpy at $0 \mathrm{~K}$ for both, indicating the possibility of reverse transformation from $\eta$ to $\gamma^{\prime}$. This reverse transformation has been observed by Heo et al. [15] in an Fe-Ni-Ti alloy, providing the misfit strain in the $\eta / \gamma$ interface acted as driving force for such a transformation. Moreover, $\eta$ phase has been reported to have different structure and chemistry in different superalloys. For instance, Pickering et al. [16] reported that $\mathrm{Nb}$ atoms replaced certain $\mathrm{Al}$ sites, leaving $\mathrm{Ti}$ and $\mathrm{Al}$ to occupy randomly the other sites. However, in another superalloy [17], it was Ta along with $\mathrm{Nb}$ that occupied the Wyckoff $2 \mathrm{a}$ sites in $\eta$ phase crystal structure.

The mechanism of $\gamma^{\prime}$ to $\eta$ transformation has been studied for decades, although more details need to be revealed. In general, it is believed that the change of crystal structure from $\mathrm{L}_{2}$ to $\mathrm{D}_{24}$ are due to the introduction of extrinsic staking faults (ESFs), leading alternations of atomic layers of $\mathrm{ABCABC}$ to $\mathrm{ABACABAC}$ stacking layers $[18,19]$. ESF fringes in $\gamma^{\prime}$ were experimentally observed using dark field transmission electron microscopy (TEM) during heating after cold deformation [19]. More recently, a direct observation of $\eta$ phase formation along two layers of deformation-induced stacking faults has been made by Smith et al. [12, 17]. The exact $\eta$ structure was confirmed via atomic resolution EDX elemental mapping. 
Although widely studied, the research of formation of $\eta$ phase from $\gamma^{\prime}$ either focused on the very initial stage involving only a few atomic layers such as in $[12,17,18]$, or skiped to the well-grown lath $\eta$ structure (or Widmanstätten structure) without observing the growth mechanisms such as in $[7,9,11]$. In between, the nucleation and thickening (growth) of "bulk" $\eta$ phase during ageing process, the effect of neighbouring phases and the exact chemical elemental diffusion during the $\eta$ growth, remain unclear. Moreover, the $\eta$ precipitation site has been observed or proposed to be at grain boundaries $[8,10,16], \gamma^{\prime} / \gamma$ interface [9] or in the centre of $\gamma^{\prime}$ [11]. This inconsistency in the precipitation sites might be related to the difference in chemical composition of the alloys and/or loading conditions used in each study. Therefore, a thorough examination of the complete process of $\eta$ phase nucleation and growth need to be addressed further to understand the formation/transformation mechanism of $\eta$ phase in nickel-based superalloy.

On the microstructure degradation in nickel-based superalloy during thermal exposure, in addition to the coarsening and aligning of $\gamma^{\prime}$, the decomposition of large size MC carbides associated with their transformation to other carbides $\left(\mathrm{M}_{23} \mathrm{C}_{6}\right.$ or $\left.\mathrm{M}_{6} \mathrm{C}\right)$ has been well documented [9]. However, another much smaller intragranular MC carbide has rarely been reported. In a nickel-based superalloy (Nimonic 263) which has similar chemical composition to Waspaloy, Zhao et al., [9] noticed two types of tiny MC carbide in comparable size of $\gamma^{\prime}$ $(\sim 300 \mathrm{~nm})$ after ageing at $850{ }^{\circ} \mathrm{C}$ for $50 \mathrm{~h}$ in addition to the normal large $\mathrm{MC}$ carbides. However, the stability and evolution (or decomposition) of this type of fine MC carbide during long-term thermal exposure has been rarely observed and reported.

In the current study, microstructure degradation during long-term ageing at elevated temperatures was reported, with a great focus on the $\eta$ phase formation and growth from $\gamma$ '. 
Waspaloy was thoroughly characterised via a serial of high-resolution characterisation techniques. It revealed the unique nucleation structure of bulk $\eta$ phase inside large $\gamma^{\prime}$ for the first time. Two paths and sequences of $\eta$ phase nucleation and growth are observed and schematically suggested. In particular, the important role of fine size MC carbide in promoting $\eta$ phase formation was investigated in terms of $\eta$ phase nucleation and growth kinetics. The reported results in the current work are believed to advance the understanding of $\eta$ phase nucleation and growth mechanism that have practical significance in alloys design and manufacture processing.

\section{Experiment procedure}

In order to investigate the precipitation behaviour of $\eta$ phase and its evolution in nickel-based superalloy during long-term thermal exposure, the Waspaloy used in the current study was aged at $780{ }^{\circ} \mathrm{C}$ for up to 10,000 h. The chemical composition of Waspaloy (wt.\%) used was $3.1 \% \mathrm{Ti}, 1.6 \% \mathrm{Al}, 19.5 \% \mathrm{Cr}, 13.5 \% \mathrm{Co}, 4.3 \% \mathrm{Mo}, 0.07 \% \mathrm{C}, 0.05 \% \mathrm{Zr}$ and $\mathrm{Ni}$. The alloy was re-melted using vacuum induction furnace. The ingot with a diameter of $80 \mathrm{~mm}$ were hot forged into rod of $40 \mathrm{~mm}$ in diameter. The rod was subjected to the standard heat treatment for this alloy following: $1070{ }^{\circ} \mathrm{C} / 4 \mathrm{~h}$, air cooling $(\mathrm{AC})+845^{\circ} \mathrm{C} / 24 \mathrm{~h}, \mathrm{AC}+760^{\circ} \mathrm{C} / 16 \mathrm{~h}, \mathrm{AC}$ [20]. The produced alloy was then cut into small specimens followed by long-term ageing at $780{ }^{\circ} \mathrm{C}$. A specimen was taken out from furnace for analysis every $500 \mathrm{~h}$. Each sample was grinded to remove oxidation scales with progressive $\mathrm{SiC}$ papers and further polished and culminated with $0.05 \mu \mathrm{m}$ colloidal silica. Both chemical etching $\left(5 \mathrm{~g} \mathrm{CuCl}_{2}, 100 \mathrm{ml}\right.$ hydrochloric acid and $100 \mathrm{ml}$ ethanol for $2 \mathrm{~s}$ to remove $\gamma^{\prime}$ precipitate) and electrolytical etching ( $10 \%$ phosphoric acid at $3-5 \mathrm{~V}$ for $3-5$ s to remove $\gamma$ matrix) methods were used for microstructure observation by using field emission gun scanning electron microscopy (FEGSEM), JEOL 7800F. The SEM is equipped with both EDS (electron dispersive X-ray 
spectroscopy) and EBSD (electron backscatter diffraction) detectors for elemental and grain size/orientation analysis, respectively. Thin foils for transmission electron microscopy (TEM, FEI-Talos 200F) observation were prepared by grinding to a thickness of $50 \sim 60 \mu \mathrm{m}$, followed by twin-jet electronic thinning using Struers Tenupol III. For this, an electrolyte of $10 \%$ perchloric acid in methanol was used at $-30{ }^{\circ} \mathrm{C}$ and $25 \mathrm{~V}$. The TEM system is equipped with a Silicon Drift Detector (SDD) for Super-EDS. The phase identification and orientation relationship were further investigated using TEM-based automated crystal orientation mapping (ACOM) and 300 kV JEOL 3010 TEM with a Precession Electron Diffraction (PED) control unit, Digistar, supplied by Nanomegas. Supporting software such as ASTAR (Nanomegas) and HKL Channel 5 software were used for post processing of the orientation data. The methodology and details of using TEM orientation mapping including ASTAR can be found in [21]. The orientation data obtained from TEM (ACOM) were further utilized to calculate geometrically necessary dislocation (GND) using an in-house Python codes. The principles and details of the calculation were reported previously in [22, 23]. GNDs in FCC and HCP structure were calculated separately for $\gamma^{\prime} / \gamma$ and $\eta$ phase, respectively, by considering their different slip systems in these two crystal structures [22, 24, 25].

\section{Results}

\subsection{General degradation of microstructure during ageing}

Fig. 1 shows the microstructure of Waspaloy after heat treatment (termed as $0 \mathrm{~h}$ ageing here). The average grain size was $\sim 72 \mu \mathrm{m}$. No evidence of strong texture was found in heat-treated sample from inverse pole figure (IPF) along longitude direction (LD) of the rod in Fig. 1a. The large number of twin boundaries was also observed during forging, see Fig. 1a. In addition to basic $\gamma^{\prime} / \gamma$ phases, other common phases in Waspaloy were also observed including $\mathrm{M}_{23} \mathrm{C}_{6}$ (M mostly stands for $\mathrm{Cr}$ ) carbides precipitating along grain boundaries (GBs) 
and $\mathrm{MC}$ (Ti, Mo for $\mathrm{M}$ ) carbides mostly precipitating inside grain with a few on GBs, as indicated by white arrows for both carbide types in Fig. 1b. It should be noted that these carbides type verification were based on phase morphology and ESD analyses identification as in [4]. This type of MC carbide, generally with large size, e.g., $>1 \mu \mathrm{m}$, is widely reported in many other superalloys. However, another type of MC carbide with much smaller size (in hundreds of nm or well below $1 \mu \mathrm{m}$ ) has been rarely reported. This type of tiny MC carbide is indicated by yellow arrows in the inset of Fig. 1b, and a typical example is shown in Fig. 1c. For convenience, the large size MC carbide and the smaller one is termed here as MC-I and MC-II, respectively. The average chemical composition for both two types of carbides (obtained from more than 10 carbides of each type) are displayed in Table 1 . The table shows high concentration of $\mathrm{Ni}(\sim 27$ wt.\%) and Ti and Mo elements in MC-II carbide whilst low concentration of $\mathrm{Ni}$ in the MC-I carbide.

Fig. 2 shows the coarsening of $\gamma^{\prime}$ during ageing up to $10000 \mathrm{~h}$. In superalloy, such a coarsening and ripening process characterised as an increase in size and decrease in volume fraction of $\gamma^{\prime}$ is the predominant degradation form, corresponding to the most of loss of strength during long-term thermal exposure or service $[9,26]$. In the current case, the average size of $\gamma^{\prime}$ increased from $\sim 70 \mathrm{~nm}(0$ h, Fig. 2a) to $\sim 240 \mathrm{~nm}$ (10000 h, Fig. 2d) and the volume fraction of $\gamma^{\prime}$ decreased from $\sim 31 \%$ to $\sim 19 \%$. Meanwhile, the morphology of $\gamma^{\prime}$ changed from spherical to near cubic. The $\gamma^{\prime}$ edge alignment along a particular direction after longterm ageing was also evident after ageing $5000 \mathrm{~h}$ (Figs. 2c and 2d). Moreover, it also demonstrates near bimodal size distribution of $\gamma^{\prime}$ in the late stage of ageing (around after $5000 \mathrm{~h}$ ), indicating simultaneous $\gamma^{\prime}$ precipitation and growth during ageing process. It should be noted that a number of exceptional large $\gamma^{\prime}$ existed after heat treatment, as indicated by the yellow arrows in Fig. 2a. These large $\gamma^{\prime}$ probably precipitated in the intermediate heat 
treatment $\left(845^{\circ} \mathrm{C} / 24 \mathrm{~h}\right)$ along with other $\gamma^{\prime}$. It seems the element segregation occurrence during solidification process promoted the abnormal growth of the large $\gamma^{\prime}$. Although volume fraction of these large $\gamma$ ' is almost negligible compared to the "normal" small $\gamma$ ', the important role of these large $\gamma^{\prime}$ on the phase evolution during prolong ageing will be described and discussed in the following sections.

Fig. 3 presents examples of phase evolution of other two phases, i.e., the decomposition of large size $\mathrm{MC}$ carbide (MC-I, Figs. 3a and 3b) and growth of $\mathrm{M}_{23} \mathrm{C}_{6}$ (Fig. 3c). The decomposition of MC-I was in an agreement with other reports following the transformation route in Eq. 1:

$\mathrm{MC}+\gamma \rightarrow \mathrm{M}_{23} \mathrm{C}_{6}+\gamma^{\prime} \ldots \ldots \ldots \ldots \ldots \ldots \ldots$ Eq. (1)

However, it shows different morphology and structure of transformed $\mathrm{M}_{23} \mathrm{C}_{6}$ and $\gamma^{\prime}$ in some cases. For instance, the $\gamma^{\prime}$ exhibits dotted-shape within $\mathrm{M}_{23} \mathrm{C}_{6}$ in Fig. 3a, while in continuous bulky shape surrounding decomposed $\mathrm{MC}$ carbide in Fig. $3 \mathrm{~b}$. Meanwhile, the $\mathrm{M}_{23} \mathrm{C}_{6}$ shows bulky shape surrounding $\mathrm{MC}$ in Fig. $3 \mathrm{a}$ whereas $\mathrm{M}_{23} \mathrm{C}_{6}$ has an elongated morphology along specific crystal direction in Fig. 3b. The growth of $\mathrm{M}_{23} \mathrm{C}_{6}$ on $\mathrm{GB}$ which extended into grain interior also exhibited specific directions (Fig. 3c) in the sample aged 6000 h. The selected area diffraction (SAD) patterns of both $\mathrm{M}_{23} \mathrm{C}_{6}$ and $\gamma / \gamma^{\prime}$ shows that $\mathrm{M}_{23} \mathrm{C}_{6}$ grew along $\{111\}$ ${ }_{\mathrm{M} 23 \mathrm{C} 6 / \gamma / \gamma}$, plane with growth direction of $<02-2>_{\mathrm{M} 23 \mathrm{C} 6 / \gamma / \gamma}$. The $\mathrm{M}_{23} \mathrm{C}_{6}$ and $\gamma / \gamma^{\prime}$ have the orientation relationship (OR): $[011]_{\mathrm{M} 23 \mathrm{C} 6}\left\|[011]_{\gamma / \gamma}, \&(02-2){ }_{\mathrm{M} 23 \mathrm{C} 6}\right\|(02-2)_{\gamma / \gamma}$, which is equivalent to the cube-to-cube $\mathrm{OR}$ of $\mathrm{M}_{23} \mathrm{C}_{6}$ and $\gamma / \gamma^{\prime}$ in [27] with different incident axis.

\subsection{Formation of extra-large (EL) $\gamma$ '}

The formation of very large size $\gamma^{\prime}$ during prolong ageing at elevated temperature $\left(780^{\circ} \mathrm{C}\right)$, was evident in the current study. Their sizes were 8-12 times larger than the adjacent "normal" 
size $\gamma^{\prime}$ in the late stage of evolution. Here, these large size $\gamma^{\prime}$ are termed as extra-large $\gamma^{\prime}$ (EL$\left.\gamma^{\prime}\right)$. Moreover, two independent formation paths of EL- $\gamma^{\prime}$ were identified. The critical and representative stages of this formation for each path along with the ageing times are displayed in Fig. 4. In the first path, Figs. 4a-c, EL- $\gamma$ ' was formed by coalescence and annexation of fine $\gamma^{\prime}$ during ageing process. An example of such coalescence of small size $\gamma^{\prime}$ in the early stage of ageing is shown in Fig. 4a and indicated by the yellow circles. However, when large $\gamma^{\prime}$ once formed, the annexation of small $\gamma^{\prime}$ by the large $\gamma^{\prime}$ would dominate the process. Two examples are presented in Fig. 4b. Finally, Fig. 4c shows an example of EL- $\gamma$ ' in the longest aged sample (10000 h). From this evolution sequence, especially the annexation process, it would be reasonable to assume the "abnormal" large $\gamma$ ' after heat treatment (Fig. 2a) dominates this formation process by annexing surrounding small $\gamma^{\prime}$. Moreover, the interface between the annexing $\gamma^{\prime}$ phases showed a curvy boundary (interface), see the marked yellow line in the inset of Fig. 4b. This clearly indicates the large "adsorption" force exerted during annexation process and thus, a considerable strain was assumed to remain in the produced EL- $\gamma$ '.

The second path of EL- $\gamma$ ' formation is MC-II carbide-based adsorption and annexation of the surrounding small $\gamma^{\prime}$, as illustrated in Figs. 4d-f. The aggregation and accumulation of surrounding small $\gamma^{\prime}$ to small MC-II carbides started even immediately after full heat treatment $(0 \mathrm{~h})$. These small $\gamma^{\prime}$ are indicated by arrows in Fig. $4 \mathrm{~d}$. Within a short period ( $100 \mathrm{~h}$ ), these individual $\gamma^{\prime}$ grew together and formed a continuous large bulk $\gamma^{\prime}$ around MC carbide (Fig. 4e). This process was followed by the further annexation of small $\gamma^{\prime}$ to form EL- $\gamma^{\prime}$ as typically shown in Fig. 4f. It seems the growth kinetic during EL- $\gamma^{\prime}$ formation was greatly accelerated in the second path, i.e., MC-based adsorption and annexation. In the examples of Fig. 4, the size of EL- $\gamma^{\prime}$ formed on MC after 1000 h (Fig. 4f) is comparable to 
the size of EL- $\gamma^{\prime}$ formed after 10 times longer time (10000 h, Fig. 4c) by mere $\gamma^{\prime}$ coalescence.

Figs. 5a and 5b show TEM images of a typical EL- $\gamma$ ' formed around MC-II carbide after $3000 \mathrm{~h}$ ageing. The SAD pattern of three phases, $\gamma^{\prime} / \gamma / \mathrm{MC}$, and separate SAD pattern for MC and $\gamma^{\prime} / \gamma$ are displayed in Figs. 5c, 5d, 5e, respectively. The SAD patterns revealed an orientation relationship between MC and $\gamma^{\prime} / \gamma:[1 \overline{1} 2]_{\gamma^{\prime} / \gamma}\left\|[110]_{\mathrm{MC}} \&(1 \overline{1} \overline{1})_{\gamma^{\prime} / \gamma}\right\|(002)_{\mathrm{MC}}$. It should be emphasised here that from the dark field (DF) image of $\gamma$ matrix in Fig. 5b, several stacking faults (SFs) both on phase boundary of EL- $\gamma^{\prime} / \mathrm{MC}$ and between MC and $\gamma$ matrix going through EL- $\gamma$ ' (as indicated by arrows in Fig. 5b) were observed. Moreover, the strain contours around EL- $\gamma^{\prime}$ in $\gamma$ channel was clearly observed. Both the SFs and strain contours indicate the possible large strain induced by the EL- $\gamma$ ' formation process around MC-II carbide.

\subsection{Two paths of $\eta$ phase nucleation and growth inside EL- $\gamma$,}

Following the formation of EL- $\gamma^{\prime}$ in two manners during ageing, it is observed that $\eta$ phase nucleated inside EL- $\gamma^{\prime}$ at different ageing time. According to the different formation path of EL- $\gamma$, there are also two nucleation paths of $\eta$ phase: $\eta$ phase nucleated either within EL- $\gamma$ ' or on the phase boundary of $\mathrm{MC} / \gamma^{\prime}$ inside EL- $\gamma$ '.

\subsubsection{First path of $\eta$ phase formation in the middle of EL- $\gamma$ '}

For the first path of $\eta$ formation, Fig. 6 shows examples of both early nucleation stage of $\eta$ phase (Figs. 6a-c, aged for $6000 \mathrm{~h}$ ) and two well-grown bulk $\eta$ phases (Fig. 6d, aged for 10000 h) inside EL- $\gamma$ '. The dark field image (Fig. 6b) from the spot reflection of $\eta$ phase in SAD pattern (Fig. 6c) exhibits the morphology of newly formed $\eta$ phase with the size of 100 
$\mathrm{nm}$ in length and $40 \mathrm{~nm}$ in width. The SAD pattern of $\gamma^{\prime} / \gamma / \eta$ in Fig. $6 \mathrm{c}$ revealed an orientation relationship of $[5 \overline{4} \overline{1} 0]_{\eta}\left\|[11 \overline{2}]_{\gamma^{\prime} / \gamma} \&(0004)_{\eta}\right\|(111)_{\gamma^{\prime} / \gamma}$. Moreover, it should be noted that SFs were observed not only through EL- $\gamma^{\prime}$, but also directly connected to newly nucleated $\eta$ phase (Fig. 6a). The grown $\eta$ phases within EL- $\gamma^{\prime}$ which have elongated to more than $300 \mathrm{~nm}$ and thickened to $\sim 180 \mathrm{~nm}$ is shown in HAADF-STEM image in Fig. 6d. The high-resolution EDS mapping of $\eta$ and EL- $\gamma^{\prime}$ together with surrounding $\gamma$ matrix and small $\gamma^{\prime}$ are also shown in Fig. 6d. As expected, the chemical elements mapping revealed a relatively higher $\mathrm{Ti}$ content in $\eta-\mathrm{Ni}_{3} \mathrm{Ti}$ compared to EL- $\gamma^{\prime}\left(\mathrm{Ni}_{3}(\mathrm{Al}, \mathrm{Ti})\right)$. Moreover, a slightly higher content of Mo was detected in $\eta$ than in EL- $\gamma^{\prime}$. Average chemical composition of $\eta$ phase is listed in Table 2. For comparison, the average chemical composition of $\gamma$ matrix, normal size $\gamma^{\prime}$ and EL- $\gamma^{\prime}$ are also listed in Table 2. For statistical reliability and to consider possible composition changes during ageing, all the elemental contents were detected on the sample aged $10000 \mathrm{~h}$ and over 10 sites were detected via TEM-EDS for each phase. It shows the consistent result with EDS mapping. Moreover, it shows higher Ti content in EL- $\gamma$ ' (12.1 wt.\%) than in normal size $\gamma^{\prime}(10.7$ wt.\%).

It has been revealed in Fig. 6 that not only single $\eta$ phase but also multiple $\eta$ (two in near perpendicular shape in Fig. 6d) could nucleate inside EL- $\gamma$ '. Furthermore, Fig. 7 shows TEMACOM mapping for multiple $\eta$ phases (numbered as 1-4) nucleated in the centre of a EL- $\gamma$ ' during ageing up to $10000 \mathrm{~h}$. The TEM-ACOM characterisation was used for better understanding of the orientation relationships between $\eta$ and EL- $\gamma^{\prime}$ as well as between each $\eta$ phases. The four plate-like shape phases inside the EL- $\gamma$ ' were confirmed to be $\eta$ phase by phase map (Fig. 7d) in combination with virtual bright field image (Fig. 7a). The IPFs (along axis $\mathrm{X}$ in Fig. $7 \mathrm{~b}$ and $\mathrm{Y}$ in Fig. 7c) together with pole figures (PFs) for each phase shown in Fig. 7e clearly indicate that all the $\eta$ had the OR with EL- $\gamma^{\prime}$ of $<1 \overline{1} 0>_{\gamma^{\prime}} \|<2 \overline{1} \overline{1} 0>_{\eta} \&\{11 \overline{1}\}_{\gamma^{\prime}}$ 
$\|\{0001\}_{\eta}$. The individual pole of $\{0001\}$ and $\{11 \overline{2} 0\}$ corresponding to each $\eta$ phase are numbered and superimposed on the PFs in Fig. 7e for direct comparison. The misorientation analyses between $\eta$ phases indicate that $\eta$ phase rotated $\sim 70^{\circ}$ around $<11 \overline{2} 0>$ axis with each other. One example is presented in the misorientation degrees change along a line between $\eta$ 1and $\eta-2$ (indicated by the white dashed line in Fig. 7b), as shown in Fig. $7 f$.

\subsubsection{Second path of $\eta$ phase formation: MC-II carbide dependent}

In the second path of $\eta$ phase formation, $\eta$ phase was observed to nucleate inside the EL- $\gamma$ ' that contained MC carbide. The backscattered electron (BSE) images in Fig. 8 show two examples of this type of $\eta$ phase formation (within one grain) in a sample aged for $8000 \mathrm{~h}$. The carbide had a black contrast while the $\eta$ phases were in slightly more whitish contrast than $\gamma^{\prime}$, probably due to containing Mo content in $\eta$ according to the composition analysis (Fig. 6e and Table 2). Two parallel $\eta$ phases nucleating closely beside MC-II carbide were observed in both examples. Moreover, all the $\eta$ phases grew in a specific direction along with MC carbide and $\gamma^{\prime}$ crystal direction, indicating the existence of their crystallographic orientation relationships.

Fig. 9 presents another example of MC-related $\eta$ phase formation inside EL- $\gamma$, which was analysed by comprehensive and a series of high-resolution characterisations including HAADF-STEM (Fig. 9a), SAD pattern for $\gamma^{\prime} / \gamma / \eta /$ MC (Figs. 9b and 9c), HRTEM (Figs. 9d-f) and HR-EDS mapping (Fig. 9g). The individual phases were well identified by these techniques combined. It shows an elongated (350 nm in length), thin (20 nm in width) $\eta$ phase (in white contrast in Fig. 9a) nucleated on the phase boundary of MC/EL- $\gamma^{\prime}$ and extended in a specific direction within an EL- $\gamma^{\prime}$ (Fig. 9a). The super-EDS mappings in Fig. 9g and EDS line scanning in Supplementary Fig. 1 show that the carbide was rich in Ti, Mo 
with a minimum content of $\mathrm{Ni}$ and should be in the form of (Ti, Mo, Ni)C. Whilst the $\eta$ mainly riches in Ti with slightly Mo segregation (the element map of Mo was $50 \%$ increase in brightness to enhance visibility), the EL- $\gamma^{\prime}$ riches in $\mathrm{Ni}, \mathrm{Al}$ and $\mathrm{Ti}$, and $\gamma$ matrix riches in $\mathrm{Ni}, \mathrm{Co}, \mathrm{Cr}$ and Mo. From the SAD patterns of all the phases (Fig. 9b and schematically suggested in Fig. 9c), the following ORs was established:

$[110]_{\gamma^{\prime} / \gamma}\left\|[11 \overline{2} 0]_{\eta}\right\|[132]_{\mathrm{MC}} \&(1 \overline{1} 1)_{\gamma^{\prime} / \gamma}\left\|(0004)_{\eta}\right\|(20 \overline{1})_{\mathrm{MC}}$

The HRTEM images in Figs. 9d-f revealed more details of $\eta$ phase growth. It is evident that $\eta$ phase elongated in a specific direction with a narrow thickness. From SAD and HRTEM images it was found that the $\eta$ phase's $\{0001\}$ planes elongated along $<1 \overline{1} 00>$ direction. Moreover, it is observed that the $\eta$ phase thickened in step-by-step in $<0001>$ direction as shown in Fig. 9d. This growth manner for $\eta$ phase has been proposed by Asgari et al. [11] and is comparable to the ledge structure of other precipitates [28]. Interestingly, the formation of secondary $\eta$ phase was also observed in Fig. 9f. It clearly shows the misorientation between the first $\eta$ and secondary one was $70^{\circ}$ around [11 20$]$ axis, which is consistent with the TEM-ACOM mapping and misorientation analysis in Fig. 7f. The lattice spacing of (0001) was measured to be $8.6 \AA$, see the inset of Fig. 9f, very close to the standard spacing $\mathrm{c}=8.3 \AA[12,16]$ in $\eta-\mathrm{Ni}_{3} \mathrm{Ti}$. This slightly higher value of $\mathrm{c}$ was probably due to the small concentration of Mo (Figs. $6 \mathrm{~d}$ and $9 \mathrm{~g}$ ) which replace some sites of Ti in $\eta$ phase.

\subsection{3 $\eta$ phase growth associated with decomposition of MC-II carbide.}

In the process of second path of $\eta$ phase formation, it is observed that $\eta$ grew in association with the decomposition of MC-II carbide. Two examples of such decomposition are presented in BSE-SEM image (Fig. 10a) and HAADF-STEM image (Fig. 10b), obtained from a sample aged at $5000 \mathrm{~h}$ (surprisingly) and $10000 \mathrm{~h}$, respectively. The BF-TEM image in Fig. 10c shows the same area in Fig. 10b and presents a better contrast of carbides. The 
selected elements of EDS mappings (Fig. 10d) of the indicated area in Fig. 10b further confirmed each phase. Interestingly, both images (Fig. 10a and Fig. 10b) from different samples show the same phase structures, i.e., one EL- $\gamma^{\prime}$ containing a big carbide without $\eta$ phase formation "merged" with another EL- $\gamma$ ' containing small carbides with $\eta$ phase inside, as noted by EL- $\gamma^{\prime}-1$ and EL- $\gamma^{\prime}-2$ in Figs. 10a and 10d. It is clear from Fig. 10 that a few small size MC carbides were located between two grown $\eta$ phases parallel to each other. Given much smaller size of these carbides in EL- $\gamma^{\prime}-2$ than the one observed in EL- $\gamma^{\prime}-1$ and the nucleation of $\eta$ phase in the second path, it is thus reasonable to assume that these small carbides derived from the previous big one which had decomposed during the $\eta$ phase growth. It seems at this stage, the growth of $\eta$ phase was largely at the expense of MC carbide rather than $\gamma^{\prime}\left(E L-\gamma^{\prime}\right)$. It is worth noting here that the decomposition process had already taken place in the sample aged for $5000 \mathrm{~h}$, which also indicates the early nucleation of $\eta$ phase with the assistance of MC carbide in this path.

The details of the same area and same $\eta$ phases in Figs. 10b and 10c were further analysed via HRTEM to characterise the growth features of $\eta$ phase, see Fig. 11. Fig. 11a is the BFTEM image of the same $\eta$ phases in Fig. $10 \mathrm{~b}$ by anticlockwise rotation of $\sim 80^{\circ}$. The SAD pattern in Fig. 11f reveals the same OR between $\eta$ and $\gamma^{\prime} / \gamma$ as established earlier in Figs. 7e and 9c. A closer look of the phases (Fig. 11b) reveals two individual $\eta$ phases numbered as $\eta$ 1 on the left and $\eta-2$ on the right, respectively. This identification was also implemented with the assistance of HR-EDS mapping in Fig. 10d. However, in between these two $\eta$ phases, there were also two structures that were very similar to the $\eta$ phase in terms of lattice morphology. Here, these two (phase) structures are termed and numbered here as $\eta^{\prime}-1$ and $\eta$ '2, respectively as shown in Fig. 11b. The HR-TEM images of $\eta-1 / \eta^{\prime}-1$ (Fig. 11c) and $\eta-2 / \eta '-$ 2 (Fig. 11e) revealed nearly three times of lattice spacing between adjacent $\{0001\}$ planes in 
$\eta$ ' than in $\eta$. This is confirmed by the diffraction spots in SAD pattern for $\eta$ phase in Fig. 11g. Each adjacent pattern spots of two parallel $\{0001\}$ planes (indicated by yellow arrows in Fig. $11 \mathrm{~g})$ were further equally divided into three spacing by another two smaller diffraction spots, as indicated by the red arrows in Fig. 11g. The Fast Fourier Transformation (FFT) analyses of individual area $(\eta / \eta$ ') further confirm that these smaller diffraction spots are corresponding to the $\eta$ ' structure. An example of these FFT in $\eta-1 / \eta$ '-1 are presented in Supplementary Fig. 2. These smaller spots resemble the feature of superlattice structure. These seemly "extra" superlattice spots were once also observed by Long et al. [29] but not been explained. Fig. $11 \mathrm{~d}$ also shows this coarse lattice structure at the tips of growing $\eta-2$. Combining these results, it is suspected that these $\eta$-similar structure (termed as $\eta$ ' here) acted as a sort of "transition structure" for the transformation from $\gamma$ ' to $\eta$ phase and the growth process of $\eta$ phase.

\section{Discussion}

\subsection{Size-dependent MC-type carbides degeneration}

It has been well documented in superalloy that during thermal exposure at elevated temperature, MC-type carbides would be transformed (degraded) to another type of carbide, $\mathrm{M}_{23} \mathrm{C}_{6}$ (riches in $\mathrm{Cr}$ ) or $\mathrm{M}_{6} \mathrm{C}$ along with the formation of $\gamma^{\prime}$, following the Equation (1) (Section 3.1) [9]. This degradation was indeed also observed in the current work, as exemplified in Figs. $3 \mathrm{a}$ and $3 \mathrm{~b}$. However, in addition to this form of degradation, there is another form of decomposition of $\mathrm{MC}$ carbide that can be only observed in small size carbides (MC-II), i.e., $\eta$ growth-associated MC carbide decomposition. On the other hand, the MC to $\eta$ transformation is not unexpected. For instance, Lvov et al. [30] reported another decomposition form of MC primary carbide in other advanced superalloy:

$\mathrm{MC}+\gamma \rightarrow \mathrm{M}_{23} \mathrm{C}_{6}+\eta \ldots \ldots \ldots \ldots \ldots \ldots \ldots . . \ldots \mathrm{Eq} .(2)$ 
Also, Qin et al. [31] reported $\eta$ phase precipitation surrounding primary MC carbides during prolong thermal exposure in a cast nickel-based superalloy. However, the decomposition of MC-II carbides reported here is different from Eq. (2). Given the formation process of EL- $\gamma$ ' ("wrapping" carbide, Fig. 4d-f), it is reasonable to deduce that MC-II carbide was enclosed and isolated by EL- $\gamma$ '. Therefore, no $\gamma$ was directily involved in the reaction as stated in Eq. (2). Moreover, there was not $\mathrm{M}_{23} \mathrm{C}_{6}$ to be observed in association with $\eta$ formation and MC-II degradation. In fact, it would be inappropriate to claim that in this case, MC-II was "transformed" to $\eta$ phase, though it seems at that stage the $\eta$ grew at the expense of MC-II carbides, see Fig. 10. This aspect will be further clarified in the following section.

This different decomposition of MC heavily depends on the size of MC carbides. It should be remembered that both reaction of Eq. (1) and Eq. (2) normally take place in large size MC carbides (MC-I). The nucleation and growth of $\eta$ phase (s) and subsequent decomposition of MC-II carbides based on the previous step, i.e., EL- $\gamma^{\prime}$ has to be formed around MC-II first. It seems reasonable that smaller carbides (MC-II) with larger surface curvature have more advantage of attracting and annexing surrounding $\gamma^{\prime}$ than that of large size carbides (MC-I), and thus have higher possibility of forming EL- $\gamma^{\prime}$. Furthermore, the difference in chemical composition between MC-I and MC-II was observed here, with higher Ni and less (Ti+Mo) contents in the latter, see Table 1. However, whether these differences in composition have effects on the stability of these two types of carbides needs further study.

Zhao et al. [9] also observed the small size MC carbides in another nickel-based superalloy (Nimonic 263) of around $300 \mathrm{~nm}$ in length, either in bulky or cylindrical shape. They hypothesised that the cylindrical MC precipitates might be remnants of the decomposing MC carbide present after the solution-annealed condition. Ding et al. [32] recently claimed, 
however, in a stainless steel, that the small $\mathrm{Nb}(\mathrm{CN})$ carbides $(<0.4 \mu \mathrm{m})$ were precipitated during ageing process after solution treatment and quenching. The detailed formation process of small size MC carbides (MC-II) in the current study needs further clarified.

\section{2. $\eta$ phase nucleation and growth}

Asguri et al. [11] proposed a model that $\eta$ phase nucleated inside $\gamma^{\prime}$ due to the passage of partials through $\gamma^{\prime}$ precipitates and the consequent stacking fault changes that leads to $\eta$ phase formation. It has also long been observed that plate-like $\eta$ phase formed after cold deformation and ageing at elevated temperature [19], but the straight-forward correlation between faulted $\gamma^{\prime}$ and $\eta$ formation, and the direct evidence of $\eta$ formation in $\gamma^{\prime}$ precipitate was not reported until recently by Smith et al. $[12,17]$. However, only a few atomic layers in consistent with $\eta$ crystal structure along the ESF (extrinsic stacking fault) were observed, and the SFs were induced by creep deformation $[12,17]$. In the present work, the bulk $\eta$ phase, of the length-scales which has rarely been report before, were observed to nucleate and grow inside extra-large size $\gamma^{\prime}$ (EL- $\gamma^{\prime}$ ) during long-term thermal exposure without external straining. Moreover, two paths of $\eta$ formation with and without the assistance of MC-II carbide were revealed.

The critical stages and sequences of $\eta$ formation in each path are schematically shown in Fig. 12. The ageing time required for initiating each stage is approximately estimated. In the first path (Fig. 12a-d), the focus is a few large size $\gamma^{\prime}$ along with other large number of smaller $\gamma^{\prime}$ after full heat treatment $(0 \mathrm{~h})$, as shown in Fig. 2a and schematically in Fig. 12a. In the following coalescence process of $\gamma^{\prime}$, the original large $\gamma^{\prime}$ acts as main site adsorbing and annexing the surrounding $\gamma^{\prime}$ to form EL- $\gamma^{\prime}$. It appears that stacking faults (SFs) are introduced inside EL- $\gamma$ ' due to the large strain produced during coalescence process (Fig. 
12b). With increasing ageing time $(\sim 6000 \mathrm{~h})$, the EL- $\gamma^{\prime}$ continues to grow, and at a point, $\eta$ phase will nucleate inside, as shown in Fig. 6a and schematically in Fig. 12c. According to numerous studies on mechanism of $\eta$ nucleation $[12,15,17,19]$, the $\eta$ will highly probably nucleate along the SFs inside EL- $\gamma$ ' here and the SFs are mostly reported to be extrinsic stacking faults (ESFs) $[12,17,19]$. With further ageing to $10000 \mathrm{~h}$, in addition to the elongating and thickening of precipitated $\eta$ phase, multiple $\eta$ phases may form, exhibiting specific orientations with each other. This scenario was clearly demonstrated in Fig. 6d, Fig. 7a and schematically shown in Fig. 12d. In the later stage of ageing, the size of EL- $\gamma^{\prime}$ (and other $\gamma^{\prime}$ phases) reaches a relatively equilibrium state and will probably not change too much, see Figs. $12 \mathrm{c}$ and $12 \mathrm{~d}$. Whereas the key features in the second path of $\eta$ formation, are the EL- $\gamma^{\prime}$ formation and subsequent $\eta$ formation surrounding tiny MC-II carbides. The aggregation and adsorption of $\gamma^{\prime}$ can be observed even at the beginning of ageing (Figs. $4 \mathrm{~d}$ and 12e). Immediately after $\sim 1000 \mathrm{~h}$ ageing, a continuous extra-large $\gamma^{\prime}$ enclosing the carbide is formed (Figs. $4 \mathrm{f}$ and 12f). As in the case of first path, SFs is induced inside $\gamma^{\prime}$ by the strain and connected to MC carbide. When the growing EL- $\gamma^{\prime}$ are large enough (probably reaches a critical size), $\eta$ nucleates on the phase boundary of carbide and EL- $\gamma$ ', and more specifically and likely, on the ESFs (Figs. 9a and 12g). With increasing ageing time, the elongating and thickening of $\eta$ follow a step-by-step evolution and are associated with the decomposition of carbide, see Figs. 10a, 10c and 12h.

Comparing the two paths of $\eta$ formation, SFs (assumed to be ESFs) are found in both paths associated with $\eta$ nucleation or existed before nucleation (Figs. $4 \mathrm{f}$ and $12 \mathrm{f}$ ). It seems the introduction of ESFs is one of necessary condition for $\eta$ formation in this study. This is consistent with the widely reported $\eta$ nucleation mechanism in literature $[12,15,17,19]$. However, as claimed by Oblak et al. [19], continued thickening normal to the plane of the 
stacking fault, periodic faulting of the $\mathrm{FCC}\left(\gamma^{\prime}\right)$ stacking sequence is necessary to propagate the $\mathrm{D}_{24}(\eta)$ crystallography. Moreover, the growth of this ESFs requires diffusion of $\mathrm{Ni}$ and Ti atoms to the Frank partial. The same authors [19] even observed that without these atoms' diffusion, the subsequent thickening of $\mathrm{Ni}_{3} \mathrm{Ti}$ phase would take place in the form of $\mathrm{L1}_{2}\left(\gamma^{\prime}\right)$ crystal structure rather than $\eta$ at ESFs. The chemical composition result (Table 2) shows that EL- $\gamma^{\prime}$ has higher content of Ti (12.1 wt.\%) than that of normal $\gamma^{\prime}(10.7$ wt.\%). In addition, it seems in the presence of MC-II carbide, the faster diffusion of Ti in carbide is more likely to occur. Given these observations, it would be reasonable to deduce that another necessary condition for $\eta$ formation is that enough high content of $\eta$ formation element(s) such as Ti is available in $\gamma^{\prime}$.

Consequently, the authors propose two criteria for $\eta$ nucleation and growth. First, the existence (or introduction) of ESFs for $\eta$ nucleation, and second, the segregation (or source) of Ti (or other $\eta$ formation elements) for further $\eta$ growth. In the present investigation, the observed ESFs was introduced by the large strain accumulation during the coalescence process of $\gamma^{\prime}$ (to form EL- $\gamma^{\prime}$ ) without external loading or deformation; While in the case of $[12,17]$ and [19], the reported ESFs were introduced by creep and cold deformation, respectively. Also, creep deformation was reported to induce superlattice intrinsic stacking faults (SISF) within $\gamma^{\prime}$ [33]. Moreover, the ESFs not only provide $\eta$ nucleation sites, but also provide fast route for atoms' diffusion [34]. In the first path of $\eta$ formation, the source of Ti came from the segregation of Ti in EL- $\gamma^{\prime}$; While in the second path, the supplement of Ti was largely provided by the MC-II carbide. The large strains reported here during coalescence process of $\gamma^{\prime}$ can be reflected by the presence of dislocations surrounding EL- $\gamma^{\prime}$, as shown in Fig. 13. The high resolution GND (geometrically necessary dislocation) mapping in Fig. 13a (the same are in Fig. 7a with 6 nm TEM-based scanning) revealed high GND density not only 
around interface of EL- $\gamma^{\prime}$ and $\gamma$ matrix, but also at interface of EL- $\gamma^{\prime}$ and $\eta$ phases. Moreover, the high GND density within $\eta$ phases and the variation of GND density along $\eta$ thickening direction indicates the highly strained condition during $\eta$ formation and growth. It should be emphasised here that this GND-type dislocation accumulation was also observed at interface of EL- $\gamma^{\prime} / \gamma$ and EL- $\gamma^{\prime} / \mathrm{MC}$ in the second path as shown in Fig. 10b, and further demonstrated in Fig. 13b (indicated by red arrows) which is the BF-TEM image of the same are in below part of Fig. 10b. Moreover, in Fig. 13b, the stacking faults (SFs) generated at the interface of EL- $\gamma^{\prime} / \mathrm{MC}$ are indicated by blue arrows, which is consistent with the observation in Fig. 5 b.

Based on the above analyses, it would be easy to compare and understand the difference in nucleation and growth kinetics of bulk $\eta$ phase in the two paths. It should be mentioned here that it is difficult to quantifying the kinetics of $\eta$ formation such as volume fraction of $\eta$ phases in each stage of ageing in the present work. This is due to, (i), the contrast between $\eta$ and EL- $\gamma^{\prime}$ is similar in SEM (see the examples in Fig. 8) and they can not be $100 \%$ distinguished in a large scale, specifically for statistical measurement; (ii) The $\eta$ formation closely related the EL- $\gamma^{\prime}$ and MC-II carbide. As pointed out in Section 3.1 and 3.2, the volume fraction of EL- $\gamma^{\prime}$ and MC-II carbide were relatively low, thus, the volume fraction of $\eta$ would be very small in overall material that cannot provide reliable statistical data in the present work. However, it is clear that the nucleation and growth of $\eta$ phase in the second path (with MC-II carbide) was much faster than in first path (without carbide), see Fig. 12. This is mainly due to the ease and availability of diffusion of Ti directly provided/supplied from carbide, and probably larger strain (thus introducing ESFs) in the second path that contributed to the faster nucleation and growth kinetics. This larger strain can be observed by the contours in Fig. 5b and reflected in the high dislocation density around EL- $\gamma$ ' in the second path as shown in Fig. 10b. Moreover, SF can act as an easy path for alloying element 
diffusion similar to that of dislocation, which indicates that larger SF, higher diffusion rates. It must be emphasised here that the stage time scale in Fig. 12 is based on the earliest time they can be observed in experiment and therefore, probably underestimate the exact $\eta$ nucleation time in each path.

According to the second path of $\eta$ formation, i.e., EL- $\gamma$ ' formed surrounding MC carbide (in 3-D), followed by the $\eta$ nucleation at interface of EL- $\gamma^{\prime} / \mathrm{MC}$, it is thus reasonable to assume that in this case, $\eta$ nucleated "inside" EL- $\gamma$ '. However, in the first path of $\eta$ formation, whether the $\eta$ nucleated "inside" EL- $\gamma$ ' (although very likely) or at the interface of EL- $\gamma$ ' $/ \gamma$ matrix needs to be verified with 3-D characterisation nanoanalytical tools.

In general, the present work revealed two formation paths of $\eta$ phases in Waspaloy, which can be used in controlling and suppressing its nucleation and growth. For instance, eliminating or avoid large $\gamma^{\prime}$ formed during heat treatment and small size MC carbide (MCII) would restrain the first and the second path of $\eta$ formation, respectively. However, it is clear that the existence of MC-II carbide is most detrimental factor in promoting $\eta$ formation.

\section{Conclusion}

The phase degradation and transformation in Waspaloy nickel-based superalloy during thermal exposure at $780{ }^{\circ} \mathrm{C}$ up to $10000 \mathrm{~h}$ were thoroughly investigated, using a series of high-resolution characterisation techniques such as HR-SEM, HR-TEM, HAADF-STEM, TEM-ACOM. Two paths of $\eta$ formation and growth in the centre of extra-large $\gamma^{\prime}$ (EL- $\left.\gamma^{\prime}\right)$ were observed. The major conclusions from this work are summarised as below:

1. In addition to the large $(>1 \mu \mathrm{m})$ primary MC carbides (MC-I), another type of MC carbide (MC-II) with relatively small size $(<1 \mu \mathrm{m})$ and higher content of Ni were observed in heat- 
treated samples. The path of decomposition of MC-II was different from the reported transformation of MC-I, i.e., MC-II was not transformed (together with $\gamma$ matrix) into either $\mathrm{M}_{23} \mathrm{C}_{6}+\gamma^{\prime}$ or $\eta+\gamma^{\prime}$ but provided a phase boundary to promote $\eta$ nucleation and provided element segregation (Ti) for $\eta$ growth.

2. Two formation paths of EL- $\gamma^{\prime}$ were observed. One path is by pure $\gamma^{\prime}$ annexation and coalescence process, in which the large size of $\gamma^{\prime}$ formed before ageing was believed to play a key role as coalescence centre during the process. Another path for EL- $\gamma^{\prime}$ formation is by $\gamma^{\prime}$ coalescence surrounding the MC-II carbide. The latter path was faster in terms of growth kinetics.

3. Following the growth of EL- $\gamma^{\prime}, \eta$ phase formed in two different paths. In the first path, $\eta$ precipitated within pure EL- $\gamma^{\prime}$ and grew at the expense of EL- $\gamma^{\prime}$. While in the second path, $\eta$ precipitated on the phase boundary between MC-II and EL- $\gamma^{\prime}$ (within EL- $\gamma^{\prime}$ ) and grew at the expense of both EL- $\gamma^{\prime}$ and MC-II. It appears that the decomposition of MC-II was directly associated with $\eta$ growth.

4. Two criteria of $\eta$ formation was proposed. First, the introduction of extrinsic stacking faults (ESFs) are needed for $\eta$ nucleation, and second, the segregation (or source) of Ti are needed for further $\eta$ growth. The ESFs were believed to be the $\gamma^{\prime}$ to $\eta$ transformation site and were introduced by the high strain in both $\eta$ formation paths. It was demonstrated that this strain was generated during $\gamma^{\prime}$ coalescence process. The segregation of $\mathrm{Ti}$ in the first $\eta$ formation path was due to the higher Ti content in EL- $\gamma$ ', while in the second path (containing MC-II), was mainly dependant on the high diffusion rate of Ti provided by neighbouring MC-II carbide.

5. The grown $\eta$ phase and EL- $\gamma^{\prime}$ had the orientation relationship of $[1 \overline{1} 0]_{\mathrm{EL}-\gamma}, \|[2 \overline{1} \overline{1} 0]_{\eta} \&$ $(11 \overline{1})_{\mathrm{EL}-\gamma^{\prime}} \|(0001)_{\eta}$. In the first $\eta$ formation path, multiple $\eta$ close to each other were also observed to nucleate. The $\eta$ phases had the misorientation of $70^{\circ}$ around $<2 \overline{1} \overline{1} 0>$ axis with 
each other. In the second $\eta$ formation path, the phases of EL- $\gamma$ ', $\eta$ and MC-II had the orientation relationship of $[110]_{\mathrm{EL}-\gamma^{\prime}}\left\|[11 \overline{2} 0]_{\eta}\right\|[132]_{\mathrm{MC}} \&(1 \overline{1} 1)_{\mathrm{EL}-\gamma^{\prime}}\left\|(0004)_{\eta}\right\|(20 \overline{1})_{\mathrm{MC}}$.

6. The growth of $\eta$ phase exhibits step-by-step feature along its growth direction and forms a transition structure during $\eta$ phase formation process.

7. The second $\eta$ formation path (MC-assisted) showed much earlier $\eta$ nucleation and faster $\eta$ growth than the first $\eta$ formation path. This is probably due to higher strain (ESFs) and higher Ti diffusion rate in the presence of MC-II. This difference in the kinetics of $\eta$ formation with and without MC-II indicates the detrimental role of tiny MC carbides (MC-II) for promoting $\eta$ nucleation and growth.

\section{Acknowledgements}

The authors would like to thank Dr. Pengfei Hu in Shanghai University and Peter Davies in Swansea University for microscopy guidance as well as facilities support in AIM (Advanced Imaging of Materials) in Swansea University.

\section{Reference:}

[1] R. Viswanathan, J.F. Henry, J. Tanzosh, G. Stanko, J. Shingledecker, B. Vitalis, R. Purgert, U.S. program on materials technology for ultra-supercritical coal power plants, J. Mater. Eng. Perform. 14(3) (2005) 281-292.

[2] J. Rösler, M. Götting, D. Del Genovese, B. Böttger, R. Kopp, M. Wolske, F. Schubert, H.-J. Penkalla, T. Seliga, A. Thoma, A. Scholz, C. Berger, Wrought Ni-Base superalloys for steam turbine applications beyond $700{ }^{\circ} \mathrm{C}$, Adv. Eng. Mater. 5(7) (2003) 469-483.

[3] G. Liu, Y. Xu, C. Yang, X. Xiao, X. Chen, X. Zhang, X. Meng, Effects of Alloy Elements on Oxidation Resistance and Stress-Rupture Property of P92 Steel, Acta Metallurgica Sinica (English Letters) 28(2) (2015) 129-138. 
[4] S. Birosca, G. Liu, R. Ding, J. Jiang, T. Simm, C. Deen, M. Whittaker, The dislocation behaviour and GND development in a nickel based superalloy during creep, Int. J. Plast 118 (2019) 252-268.

[5] Y. Xu, C. Yang, X. Xiao, X. Cao, G. Jia, Z. Shen, Evolution of microstructure and mechanical properties of Ti modified superalloy Nimonic 80A, Mater. Sci. Eng. A 530 (2011) 315-326.

[6] Y. Xu, L. Zhang, J. Li, X. Xiao, X. Cao, G. Jia, Z. Shen, Relationship between Ti/Al ratio and stress-rupture properties in nickel-based superalloy, Mater. Sci. Eng. A 544 (2012) 48-53. [7] F. Long, Y.S. Yoo, C.Y. Jo, S.M. Seo, Y.S. Song, T. Jin, Z.Q. Hu, Formation of $\eta$ and $\sigma$ phase in three polycrystalline superalloys and their impact on tensile properties, Mater. Sci. Eng. A 527(1-2) (2009) 361-369.

[8] J.P. Shingledecker, G.M. Pharr, The Role of Eta phase formation on the creep strength and ductility of INCONEL alloy 740 at $1023 \mathrm{~K}\left(750^{\circ} \mathrm{C}\right)$, Metallurgical and Materials Transactions A 43(6) (2012) 1902-1910.

[9] J.C. Zhao, V. Ravikumar, A.M. Beltran, Phase precipitation and phase stability in nimonic 263, Metallurgical and Materials Transactions A 32(6) (2001) 1271-1282.

[10] N.D. Evans, P.J. Maziasz, R.W. Swindeman, G.D. Smith, Microstructure and phase stability in INCONEL alloy 740 during creep, Scr. Mater. 51(6) (2004) 503-507.

[11] S. Asgari, R. Sharghi-Moshtaghin, M. SadeghAhmadi, P. Pirouz, On phase transformations in a Ni-based superalloy, Philos. Mag. 93(10-12) (2013) 1351-1370.

[12] T. Smith, B. Esser, N. Antolin, A. Carlsson, R. Williams, A. Wessman, T. Hanlon, H. Fraser, W. Windl, D. McComb, Phase transformation strengthening of high-temperature superalloys, Nature communications 7 (2016) 13434.

[13] D.H. Le, C. Colinet, P. Hicter, A. Pasturel, Theoretical description of phase equilibrium in the nickel-titanium system, J. Phys.: Condens. Matter 3(50) (1991) 9965-9974. 
[14] J. Xu, W. Lin, A.J. Freeman, Electronic structure and phase stability of $A_{3} \mathrm{Ti}(A=\mathrm{Fe}, \mathrm{Co}$, Ni, and Cu), Phys. Rev. B 48(7) (1993) 4276-4286.

[15] Y.U. Heo, M. Takeguchi, K. Furuya, H.C. Lee, Transformation of $\mathrm{DO}_{24} \eta-\mathrm{Ni}_{3} \mathrm{Ti}$ phase to face-centered cubic austenite during isothermal aging of an Fe-Ni-Ti alloy, Acta Mater. 57(4) (2009) 1176-1187.

[16] E. Pickering, H. Mathur, A. Bhowmik, O. Messé, J. Barnard, M. Hardy, R. Krakow, K. Loehnert, H. Stone, C. Rae, Grain-boundary precipitation in Allvac 718Plus, Acta Mater. 60(6) (2012) 2757-2769.

[17] T.M. Smith, B.D. Esser, N. Antolin, G.B. Viswanathan, T. Hanlon, A. Wessman, D. Mourer, W. Windl, D.W. McComb, M.J. Mills, Segregation and $\eta$ phase formation along stacking faults during creep at intermediate temperatures in a Ni-based superalloy, Acta Mater. 100 (2015) 19-31.

[18] B.H. Kear, J.M. Oblak, A.F. Giamei, Stacking faults in gamma prime $\mathrm{Ni}_{3}(\mathrm{Al}, \mathrm{Ti})$ precipitation hardened nickel-base alloys, Metallurgical Transactions 1(9) (1970) 2477.

[19] J.M. Oblak, W.A. Owczarski, B.H. Kear, Heterogeneous precipitation of metastable $\gamma^{\prime}-$ $\mathrm{Ni}_{3} \mathrm{Ti}$ in a nickel-base alloy, Acta Metall. 19(4) (1971) 355-363.

[20] Z. Yao, M. Zhang, J. Dong, Stress Rupture Fracture Model and Microstructure Evolution for Waspaloy, Metallurgical and Materials Transactions A 44(7) (2013) 30843098 .

[21] E.F. Rauch, M. Véron, Automated crystal orientation and phase mapping in TEM, Mater. Charact. 98 (2014) 1-9.

[22] S. Birosca, F. Di Gioacchino, S. Stekovic, M. Hardy, A quantitative approach to study the effect of local texture and heterogeneous plastic strain on the deformation micromechanism in RR1000 nickel-based superalloy, Acta Mater. 74 (2014) 110-124. 
[23] G. Liu, J. Salvat Cantó, S. Winwood, K. Rhodes, S. Birosca, The effects of microstructure and microtexture generated during solidification on deformation micromechanism in IN713C nickel-based superalloy, Acta Mater. 148 (2018) 391-406.

[24] T.B. Britton, S. Birosca, M. Preuss, A.J. Wilkinson, Electron backscatter diffraction study of dislocation content of a macrozone in hot-rolled Ti-6Al-4V alloy, Scr. Mater. 62(9) (2010) 639-642.

[25] Z. Wang, C. Cochrane, T. Skippon, Q. Dong, M.R. Daymond, Dislocation evolution at a crack-tip in a hexagonal close packed metal under plane-stress conditions, Acta Mater. 164 (2019) 25-38.

[26] A. Baldan, Review Progress in Ostwald ripening theories and their applications to the $\gamma^{\prime}-$ precipitates in nickel-base superalloys Part II Nickel-base superalloys, Journal of Materials Science 37(12) (2002) 2379-2405.

[27] Y. Xu, Q. Ran, J. Li, J. Peng, X. Xiao, X. Cao, G. Jia, Strengthening behavior of Nb in the modified Nimonic 80A, Mater. Sci. Eng. A 569 (2013) 27-40.

[28] G.C. Weatherly, The structure of ledges at plate-shaped precipitates, Acta Metall. 19(3) (1971) 181-192.

[29] F. Long, Y.S. Yoo, C.Y. Jo, S.M. Seo, H.W. Jeong, Y.S. Song, T. Jin, Z.Q. Hu, Phase transformation of $\eta$ and $\sigma$ phases in an experimental nickel-based superalloy, J. Alloys Compd. 478(1) (2009) 181-187.

[30] G. Lvov, V. Levit, M. Kaufman, Mechanism of primary MC carbide decomposition in Ni-base superalloys, Metallurgical and Materials Transactions A 35(6) (2004) 1669-1679.

[31] X.Z. Qin, J.T. Guo, C. Yuan, C.L. Chen, J.S. Hou, H.Q. Ye, Decomposition of primary MC carbide and its effects on the fracture behaviors of a cast Ni-base superalloy, Mater. Sci. Eng. A 485(1) (2008) 74-79. 
[32] R. Ding, J. Yan, H. Li, S. Yu, A. Rabiei, P. Bowen, Microstructural evolution of Alloy 709 during aging, Mater. Charact. 154 (2019) 400-423.

[33] Y.M. Eggeler, J. Müller, M.S. Titus, A. Suzuki, T.M. Pollock, E. Spiecker, Planar defect formation in the $\gamma^{\prime}$ phase during high temperature creep in single crystal CoNi-base superalloys, Acta Mater. 113 (2016) 335-349.

[34] P. Kontis, Z. Li, D.M. Collins, J. Cormier, D. Raabe, B. Gault, The effect of chromium and cobalt segregation at dislocations on nickel-based superalloys, Scr. Mater. 145 (2018) 7680.

\section{Captions of Tables and Figures:}

Table 1. Average chemical composition (wt.\%) of large MC carbide (MC-I) and small MC carbide (MC-II).

Table 2. Average chemical composition (wt.\%) of $\gamma$ matrix, normal size $\gamma^{\prime}$, EL- $\gamma^{\prime}$ and $\eta$ phase after $10000 \mathrm{~h}$ ageing.

Fig. 1 Basic microstructure of Waspaloy after heat treatment ( $0 \mathrm{~h}$ ageing). (a) IPF (inverse pole figure) along longitude direction (LD) of rod showing typical grain size and orientation; (b) $\mathrm{M}_{23} \mathrm{C}_{6}$ carbides precipitated along grain boundary. Large size MC-type carbides (termed as MC-I here) precipitated both on GB and in grain interior. The inset of the magnified area shows the small size MC-type carbides (termed as MC-II, indicated by the yellow arrows); (c) High magnification image of MC-II carbide together with the morphology of $\gamma^{\prime}$.

Fig. 2 Typical size and morphology of $\gamma^{\prime}$ during long-term ageing process. (a) After heat treatment (0 h); (b) After 1000 h; (c) After 5000 h; (d) After 10000 h. Notice a few of large size $\gamma^{\prime}$ after heat treatment in (a) (indicated by the yellow arrows). 
Fig. 3 Decomposition of large MC-type carbides (MC-I) (a-b) and directional growth of $\mathrm{M}_{23} \mathrm{C}_{6}$ (c) during ageing. (a-b) Second electron (SE) image and (c) Bright field (BF) TEM image; (d) Selected area diffraction (SAD) pattern of $\gamma^{\prime} / \gamma / \mathrm{M}_{23} \mathrm{C}_{6}$ in (c). Ageing time: $10000 \mathrm{~h}$ in (a-b) and $6000 \mathrm{~h}$ in (c). Notice the different etching method in (a) and (b) resulting in different contrast of $\gamma^{\prime}$. Note: the holes in (c) are due to preferential etching of the particles on grain boundary during twin-jet polishing.

Fig. 4 Two paths of extra-large $\gamma^{\prime}$ (EL- $\gamma^{\prime}$ ) formation. (a-c) EL- $\gamma^{\prime}$ formed by coalescence and annexation of $\gamma^{\prime}$. Circled areas in (a) show two examples of early coalescence. The yellow line in the inset of (b) shows the curved interfaces of merged $\gamma^{\prime}$. (d-f) EL- $\gamma^{\prime}$ formed by surrounding small MC-type carbide (MC-II). Critical stages of formation are presented respectively. Note the much faster formation of EL- $\gamma^{\prime}$ in the second path (d-f).

Fig. 5 EL- $\gamma^{\prime}$ formed by surrounding MC-II in a sample of $3000 \mathrm{~h}$ ageing. (a) BF-TEM image; (b) Dark field (DF) image of $\gamma$ matrix in the same area of (a). Note the strain contour around the EL- $\gamma^{\prime}$ and the stacking faults (SFs) within EL- $\gamma^{\prime}$. (c) SAD pattern of $\gamma^{\prime} / \gamma / M C$; (d) and (e) SAD pattern of MC and $\gamma^{\prime} / \gamma$, respectively.

Fig. 6 Nucleation and growth of $\eta$ phase within EL- $\gamma$ '. (a-c) Nucleation of $\eta$ observed in a sample of $6000 \mathrm{~h}$ ageing. (a) BF image; (b) DF image of $\eta$; (c) SAD pattern of $\gamma^{\prime} / \gamma / \eta$. (d) HAADF-STEM image showing two well-grown $\eta$ phases within EL- $\gamma$ ' and corresponding Super-EDS elemental mapping of the whole area, observed in a sample aged $10000 \mathrm{~h}$.

Fig. 7 Multiple precipitation and growth of four $\eta$ phases within EL- $\gamma$ ' from sample of 10000 $\mathrm{h}$ ageing, characterised by TEM-ACOM mapping and pole figures. (a) Virtual bright field image; Four $\eta$ phases are numbered as 1 4. IPF figure along axis X (b) and Y (c); (d) Phase map. (e) Pole figure for $\eta$ and $\gamma^{\prime} / \gamma$; Each pole corresponding to individual $\eta$ phase are numbered in PF of $\{11 \overline{2} 0\}$ and $\{0001\}$. (f) Misorientation between $\eta-1$ and $\eta-2$. The 
scanning line is shown as white line in (b). (g) Colour key for orientation in (b-c). Scanning step size was $6 \mathrm{~nm}$.

Fig. 8 Backscattered electron (BSE) images showing $\eta$ phase formation along MC carbide within EL- $\gamma$ ' from sample of $8000 \mathrm{~h}$ ageing. The phases in black contrast are MC-II carbides, and the white contrast are $\eta$ phases. Notice the very slight contrast difference between $\eta$ and EL- $\gamma$ ' due to close chemical compositions in two phases.

Fig. 9 Comprehensive characterization of a $\eta$ phase formation along MC-II carbide within EL- $\gamma$ ' using HR-TEM and Super-EDS. (a) HAADF-STEM image showing the MC carbide (blocky shape in black in the middle), $\eta$ phase (elongated narrow shape in white colour adjacent to carbide) and surrounding EL- $\gamma^{\prime}$; (b) SAD pattern of the four phases: $\gamma^{\prime} / \gamma / \eta / \mathrm{MC}$; (c) Schematic diagraph of SAD showing detailed orientation relationship in (b); (d-f) HRTEM images of magnified areas marked as red box in (a), showing the details of growth of $\eta$ phase. (g) EDS mapping of the phase formation area including the four phases. The mapped area is indicated in the black box in (a).

Fig. $10 \mathrm{MC}$-II carbides decomposition associated with $\eta$ phase growth along carbide within EL- $\gamma^{\prime}$. (a) BSE image from a sample aged $5000 \mathrm{~h}$, showing one intact carbide and two decomposed small carbides in the middle of EL- $\gamma^{\prime}$. Note the slight contrast (whitish) of $\eta$ in the middle of EL- $\gamma$ ' along decomposed carbides. (b) HAADF-STEM image of similar structure (decomposed MC carbides associated with elongated $\eta$ in the middle of EL- $\gamma^{\prime}$ ) from a sample of $10000 \mathrm{~h}$ ageing. (c) BF-TEM image of the same area in (b). (d) EDS mapping of the area in the red box in (b), showing parts of key element distribution to confirm the phases and their interaction. The whole EL- $\gamma^{\prime}$ in two sites can be regarded by the merge of two EL- $\gamma^{\prime}$ $\left(E L-\gamma^{\prime}-1\right.$ and EL- $\left.\gamma^{\prime}-2\right)$ as indicated in the figures.

Fig. 11 The growth sequence of $\eta$ phase. (a) BF-STEM image of two parallel $\eta$ phases, part of the same area in Fig. 10b and 10c (rotate the images). (b) Magnified image of the yellow 
box area in (a), showing growth details of two $\eta$ phases. (c) (d) and (e) HRTME images of specific areas in red boxes in (b). (f) SAD pattern of left $\eta(\eta-1)$ and its adjacent $\gamma^{\prime} / \gamma$. (g) Magnified SAD pattern of the red box area in (f). Note the superlattice points as indicated by red arrows in (g).

Fig. 12 Schematic illustration of two formation paths of EL- $\gamma$ ' and subsequently, two paths of $\eta$ phase nucleation and growth in the centre of EL- $\gamma^{\prime}$. (a-d) Path 1 and (e-h) Path 2. (a) Initial small $\gamma^{\prime}$ with few large size $\gamma^{\prime}$ after heat treatment ( $0 \mathrm{~h}$ ageing); (b) Coalescence of $\gamma^{\prime}$ around large size $\gamma^{\prime}$; (c) After EL- $\gamma^{\prime}$ reach a critical size, $\eta$ nucleated in the centre of EL- $\gamma^{\prime}$; (d) $\eta$ growth or multiple $\eta$ nucleation and growth at the expanse of EL- $\gamma$ '. (e) Small size MC carbides (MC-II) with fine $\gamma^{\prime}$ precipitating on them during heat treatment; (f) $\gamma^{\prime}$ aggregated around the MC, forming EL- $\gamma^{\prime}$; (g) $\eta$ phase nucleated on the phase boundary of MC and EL- $\gamma^{\prime}$ within EL- $\gamma^{\prime}$; (h) Growth of $\eta$ phase at the expense of both EL- $\gamma$ ' and MC carbides. Stacking faults (SFs) were induce inside EL- $\gamma$ ' during the process. Note the rough time when the phases structure started to form are also provided in the graph for each stage in each path. The time is based on the earliest time they can be observed in experiment and therefore, probably underestimate the exact $\eta$ nucleation time for each path.

Fig. 13 High strain distribution surrounding EL- $\gamma^{\prime}$ reflected by high dislocation density. (a) GND (geometrically necessary dislocation) mapping in an EL- $\gamma^{\prime}$ in which multiple $\eta$ phases precipitated. It is the same area in Figs. 7a-d, i.e., TEM-based orientation mapping using step size of $6 \mathrm{~nm}$. The GND map is combined after separated calculation for $\gamma^{\prime} / \gamma$ and $\eta$ using FCC and HCP structure, respectively. The unit is $\log \mu \mathrm{m}^{-2}$. (b) An example of dislocations (GNDs) surrounding an EL- $\gamma^{\prime}$ with a MC carbide in the middle, characterised by BF-TEM image. It is the same area of below half (EL- $\left.\gamma^{\prime}-2\right)$ in Figs. 10b and 10d. 
Supplementary Fig. 1 EDS line scanning of the MC-II carbide, EL- $\gamma$ ' and $\eta$, the same area in Fig. 9g. Only elements of C, Ti, Ni and Mo are selected and presented here. It shows the MC carbide riches in $\mathrm{Ti}$, Mo and small content of $\mathrm{Ni}$. $\eta$ riches in $\mathrm{Ni}$, Ti and small content of Mo. A slightly higher content of Mo in $\eta$ was observed than in EL- $\gamma$ ', which is consistent with the EDS mapping in Figs. 6d and 9g.

Supplementary Fig. 2 Fast Fourier Transformation (FFT) of $\eta-1$ and/or $\eta$ '-1 in the same area of Fig. 11. Other information (diffraction, location) of $\eta-1$ and $\eta '-1$ can be found in Fig. 11 and the chemical information can be found in EDS mapping in Fig. 10. 
Click here to download high resolution image
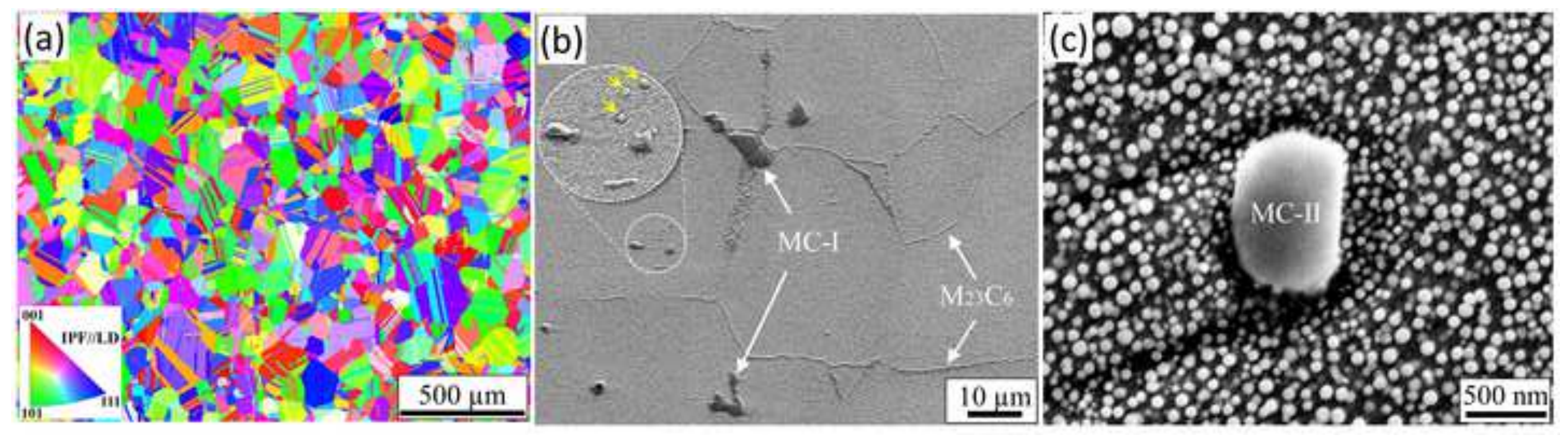

Click here to download high resolution image 
(a) $0 \mathrm{~h}$

(b) $1000 \mathrm{~h}$

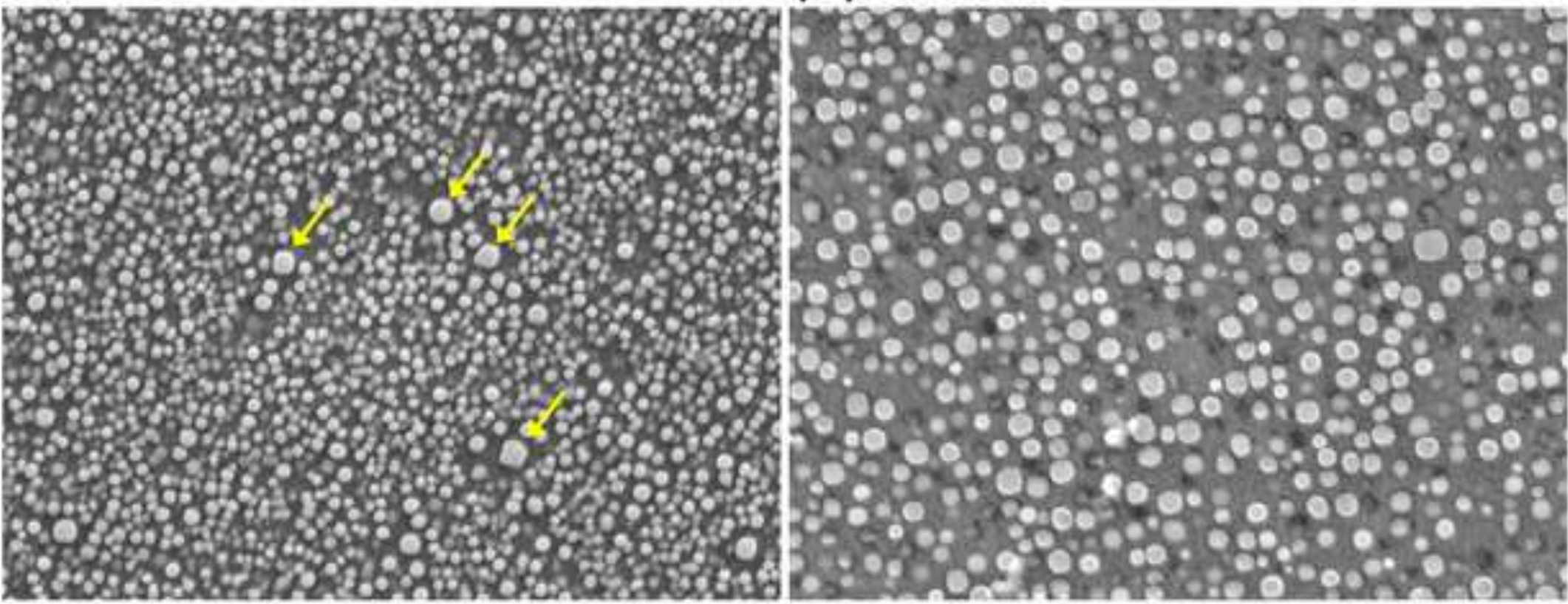

(c) $5000 \mathrm{~h}$

(d) $10000 \mathrm{~h}$

$1 \mu \mathrm{m}$
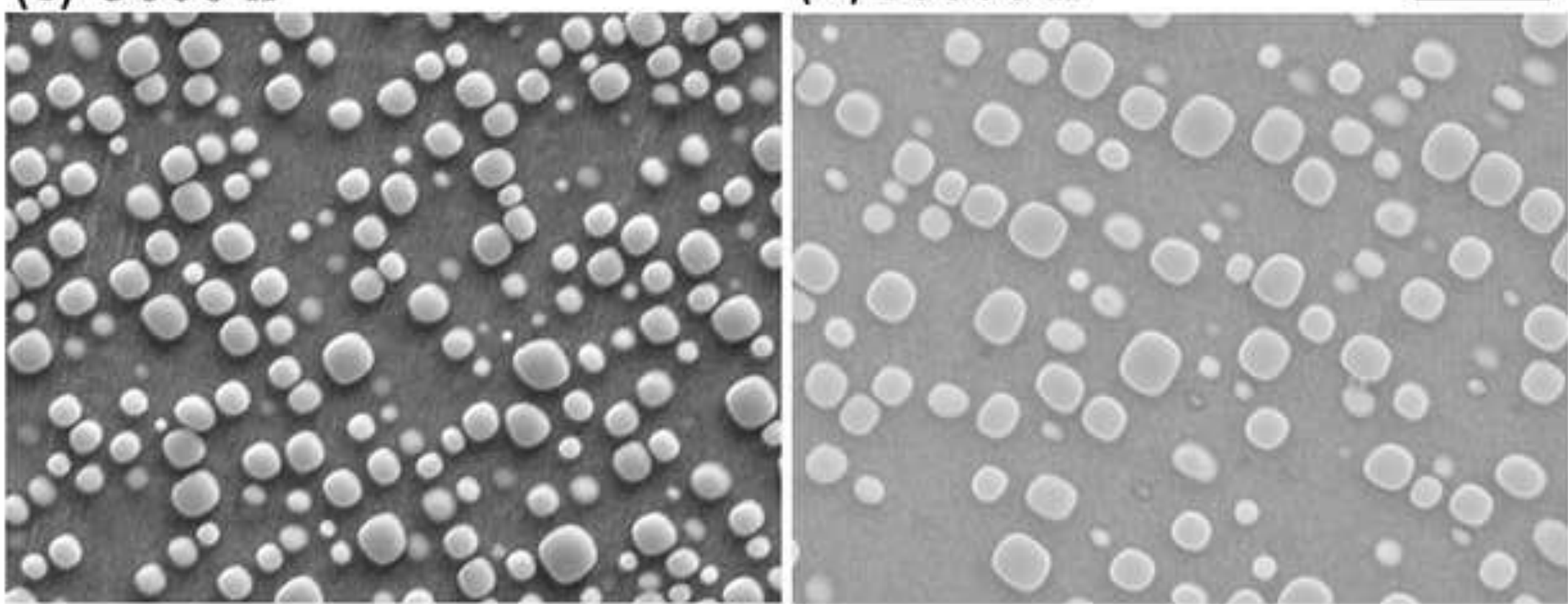

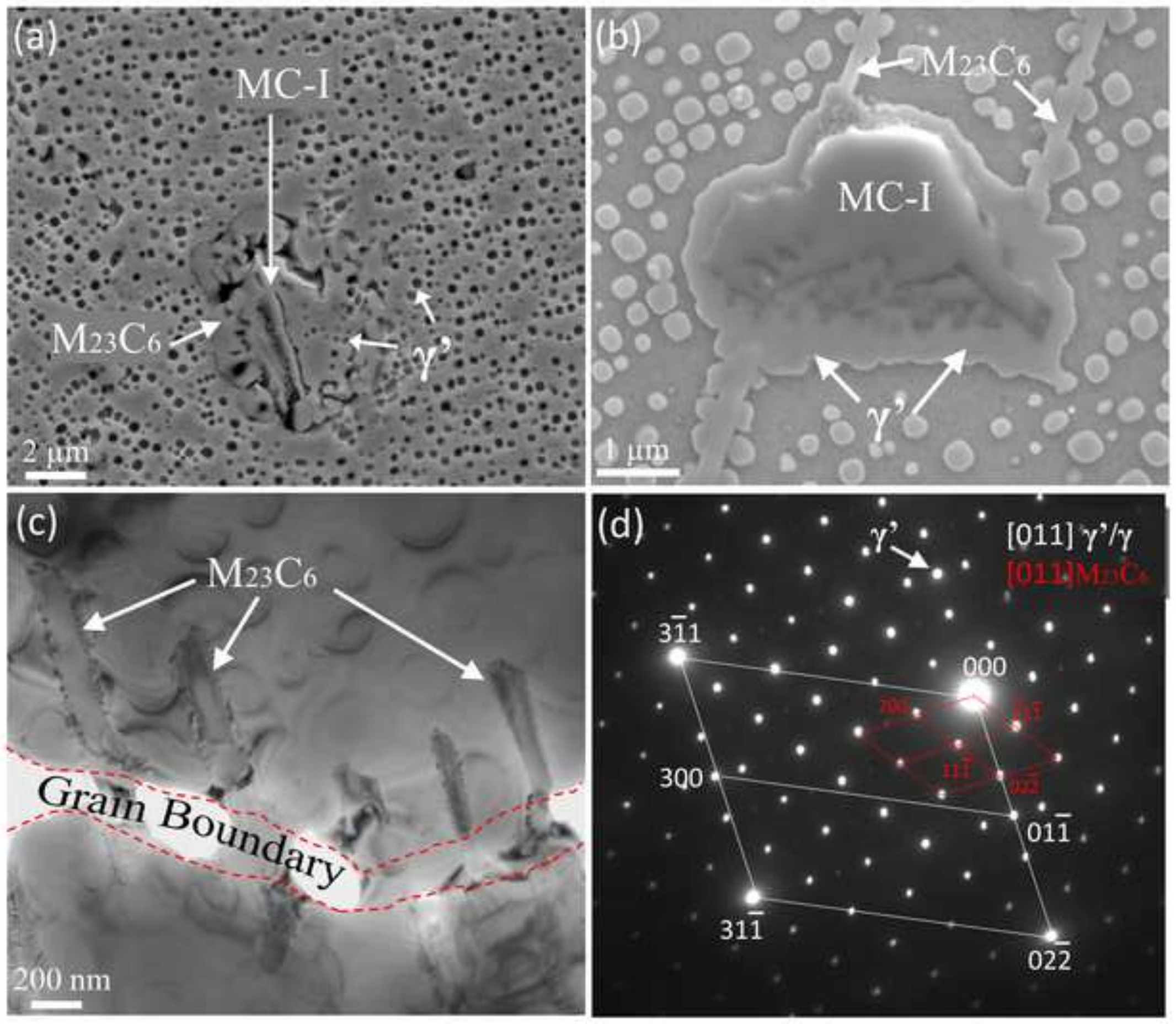
(a) $2000 \mathrm{~h}$

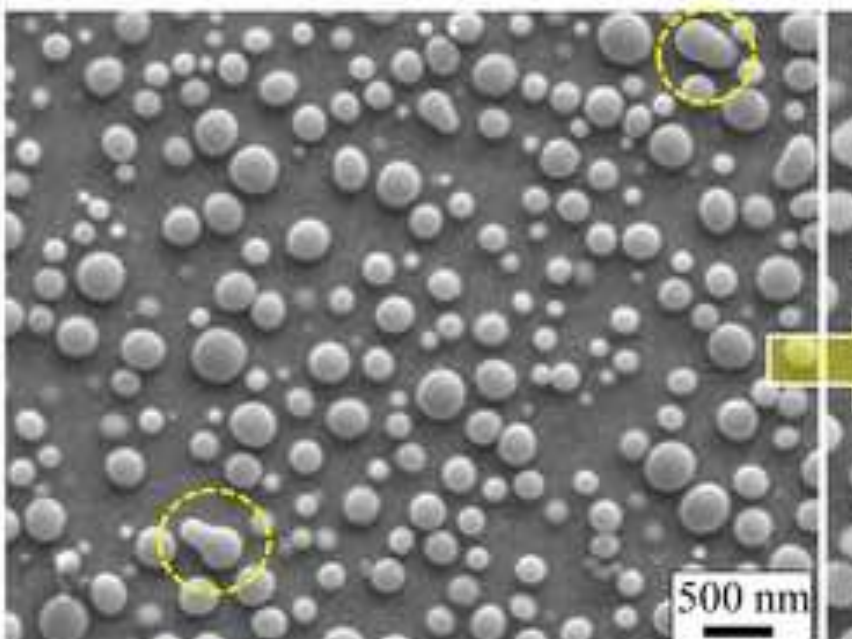

(b) $4000 \mathrm{~h}$

(c) $10000 \mathrm{~h}$

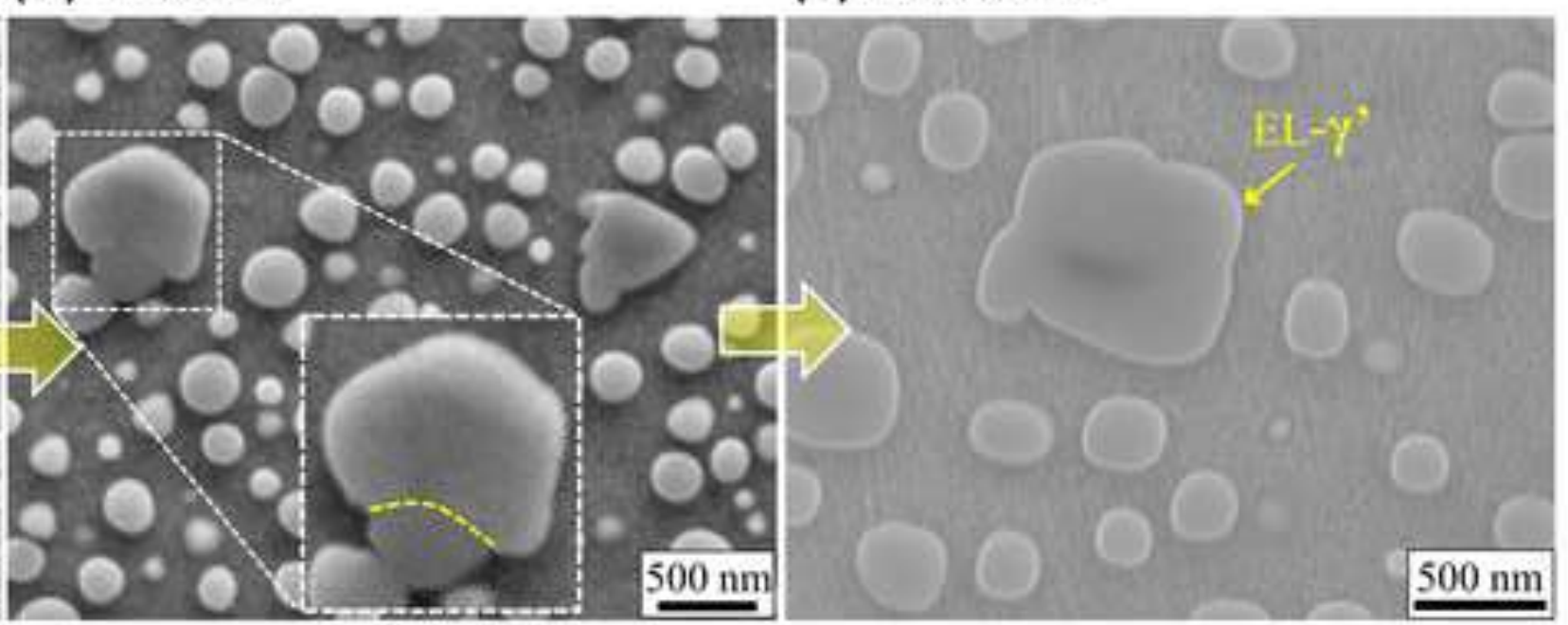

(d) $0 \mathrm{~h}$

(e) $100 \mathrm{~h}$

(f) $1000 \mathrm{~h}$

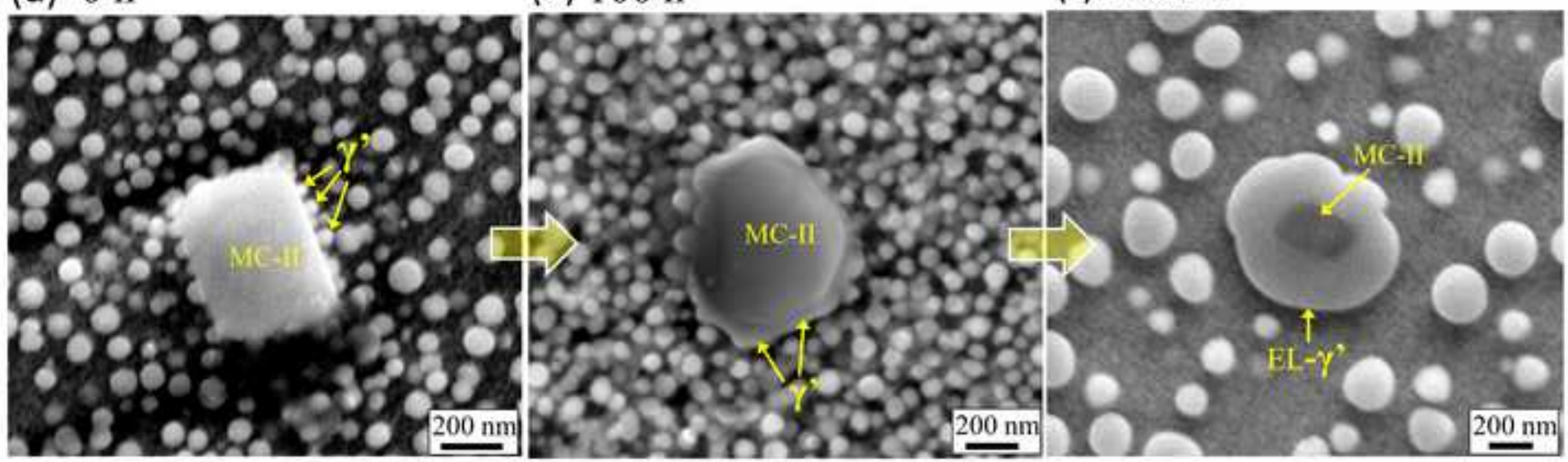


Click here to download high resolution image

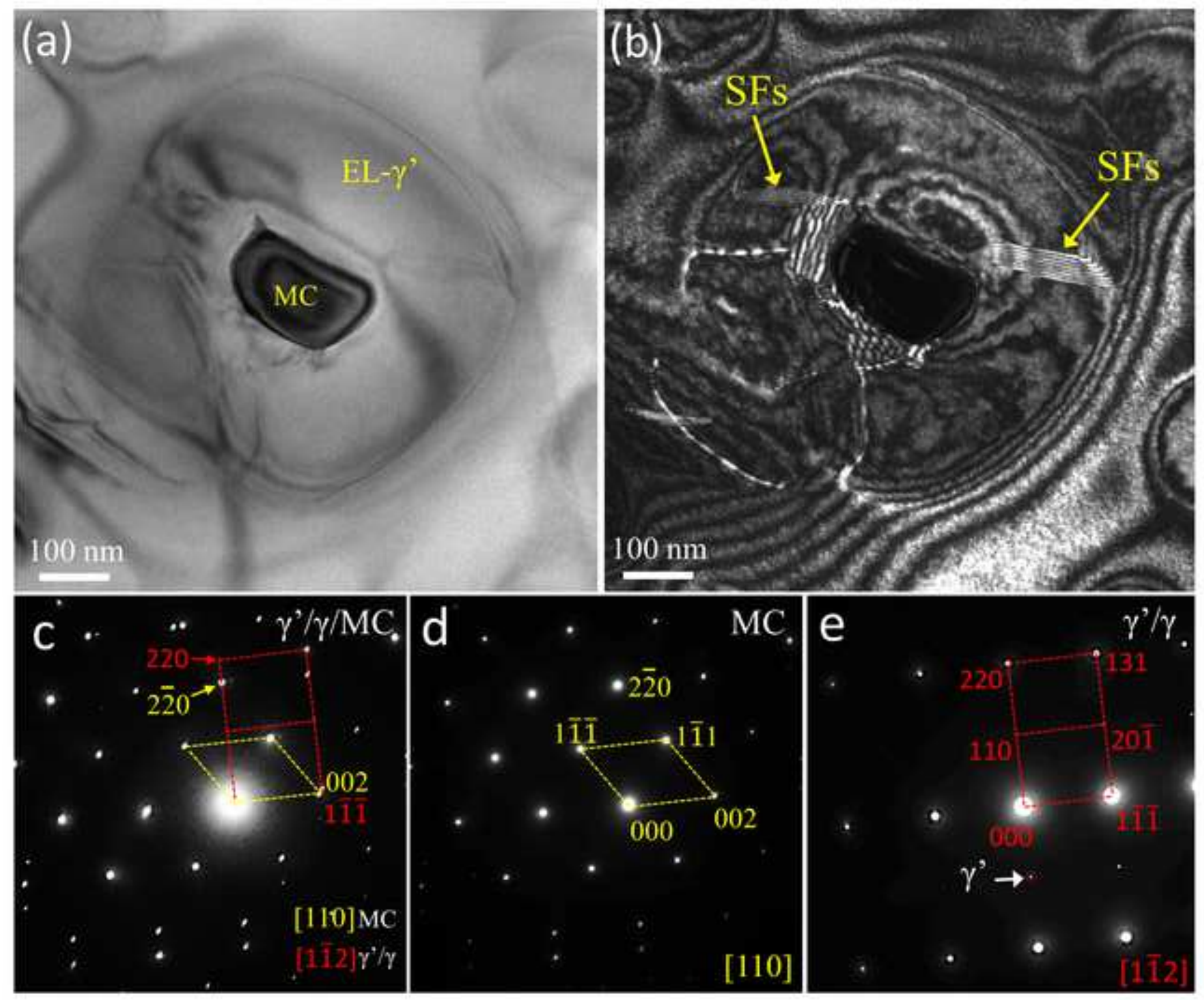




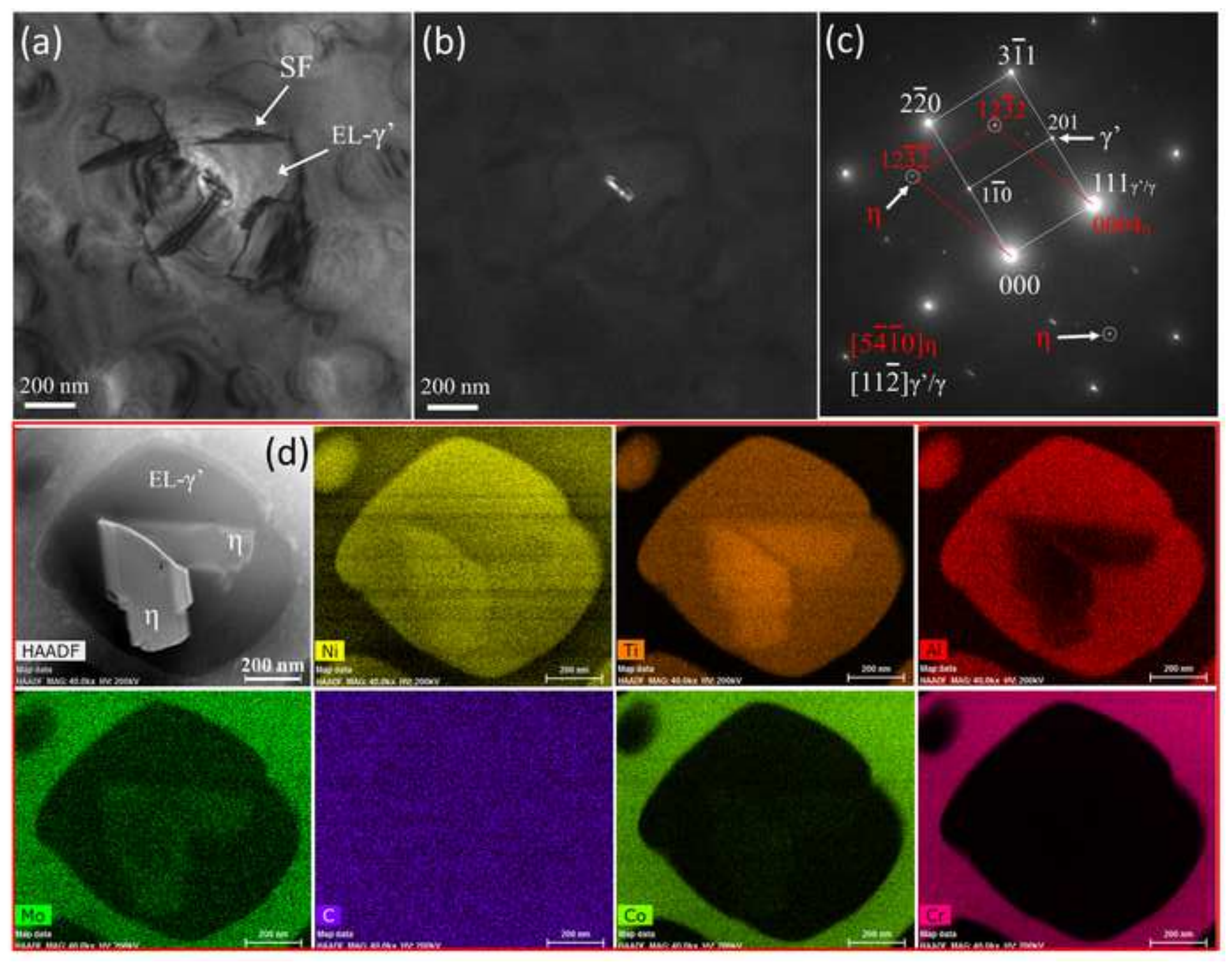

to download high resolution image (1) 

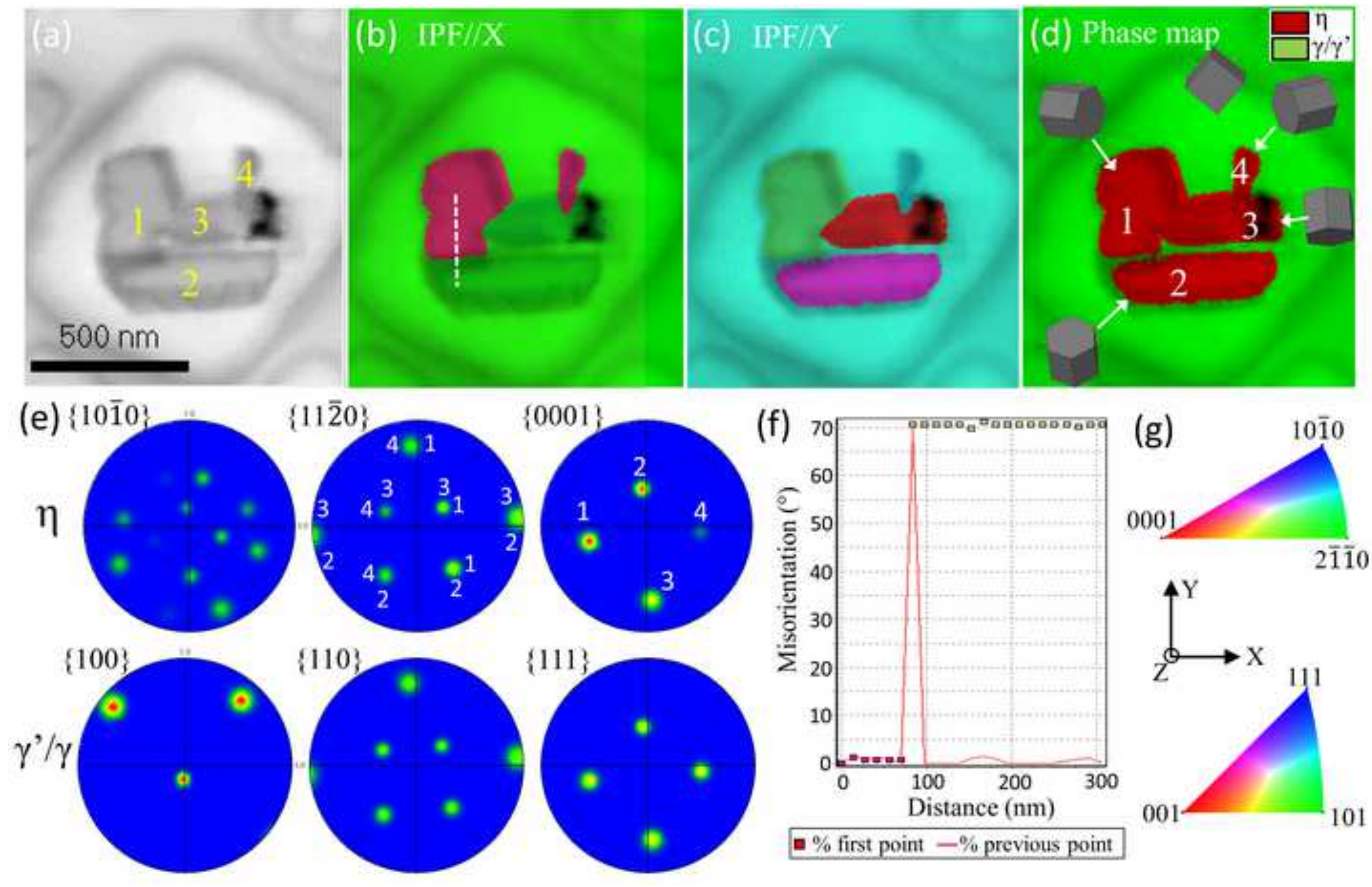

n $\%$ first point $-\%$ previous point 
Click here to download high resolution image

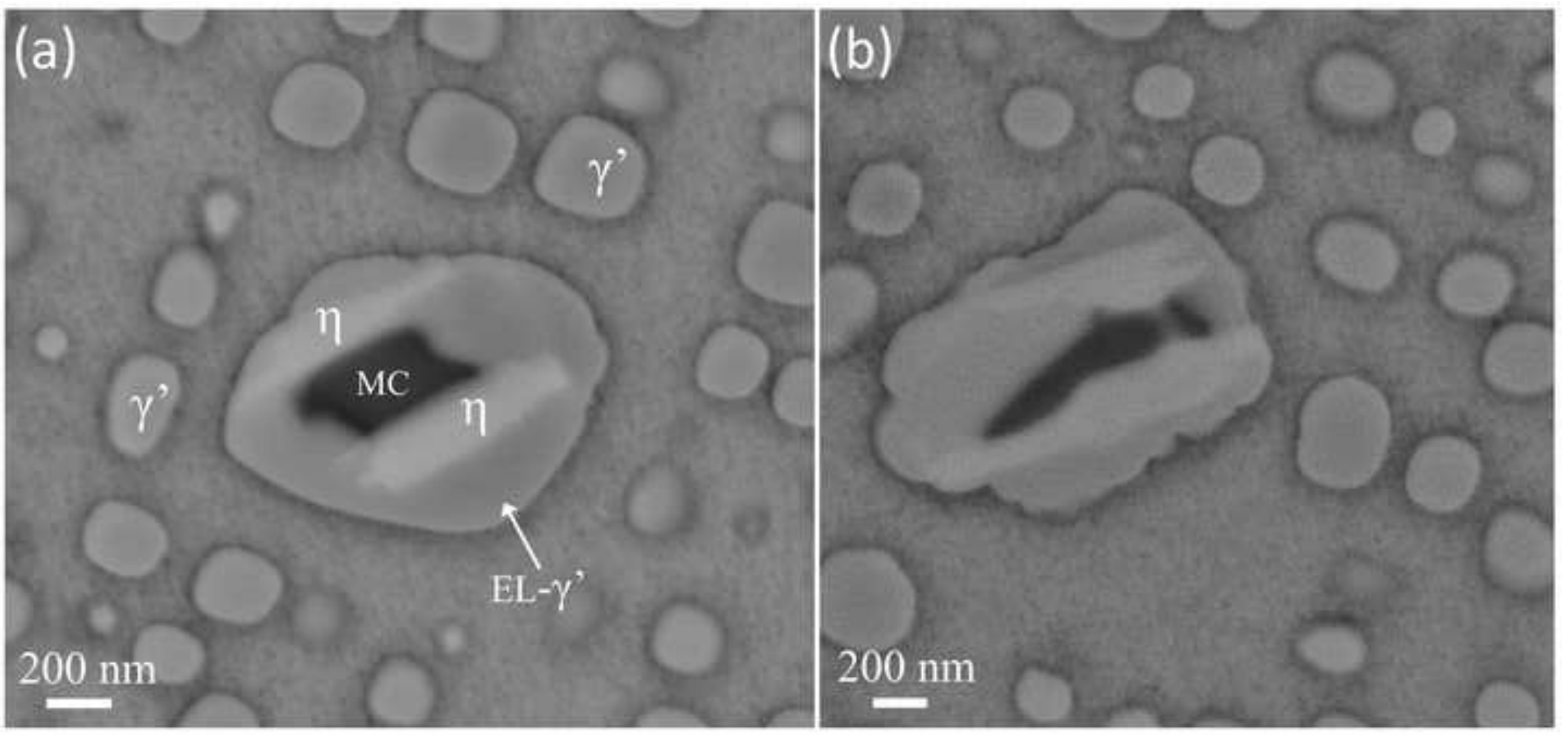


Click here to download high resolution image
Click 9
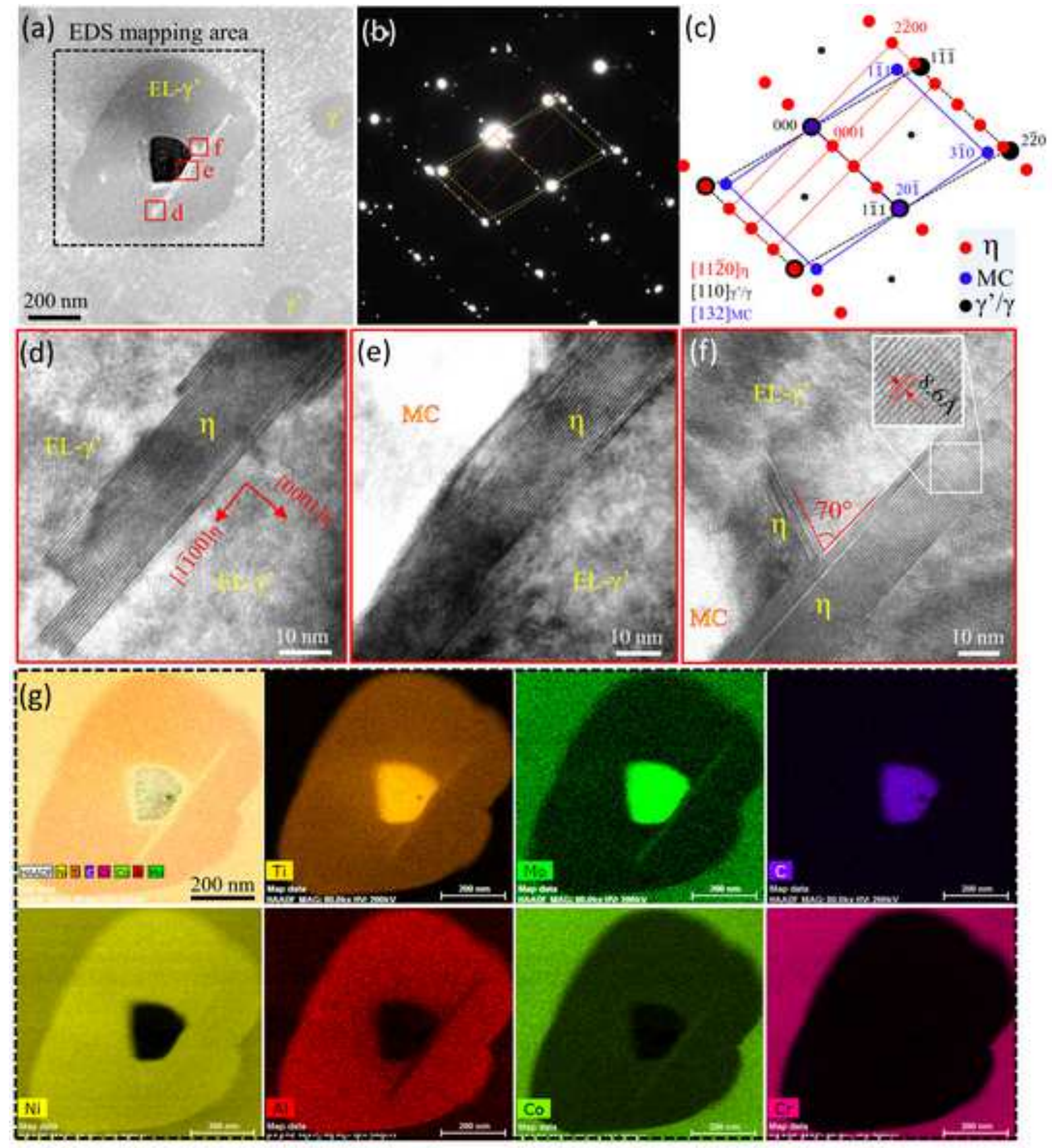


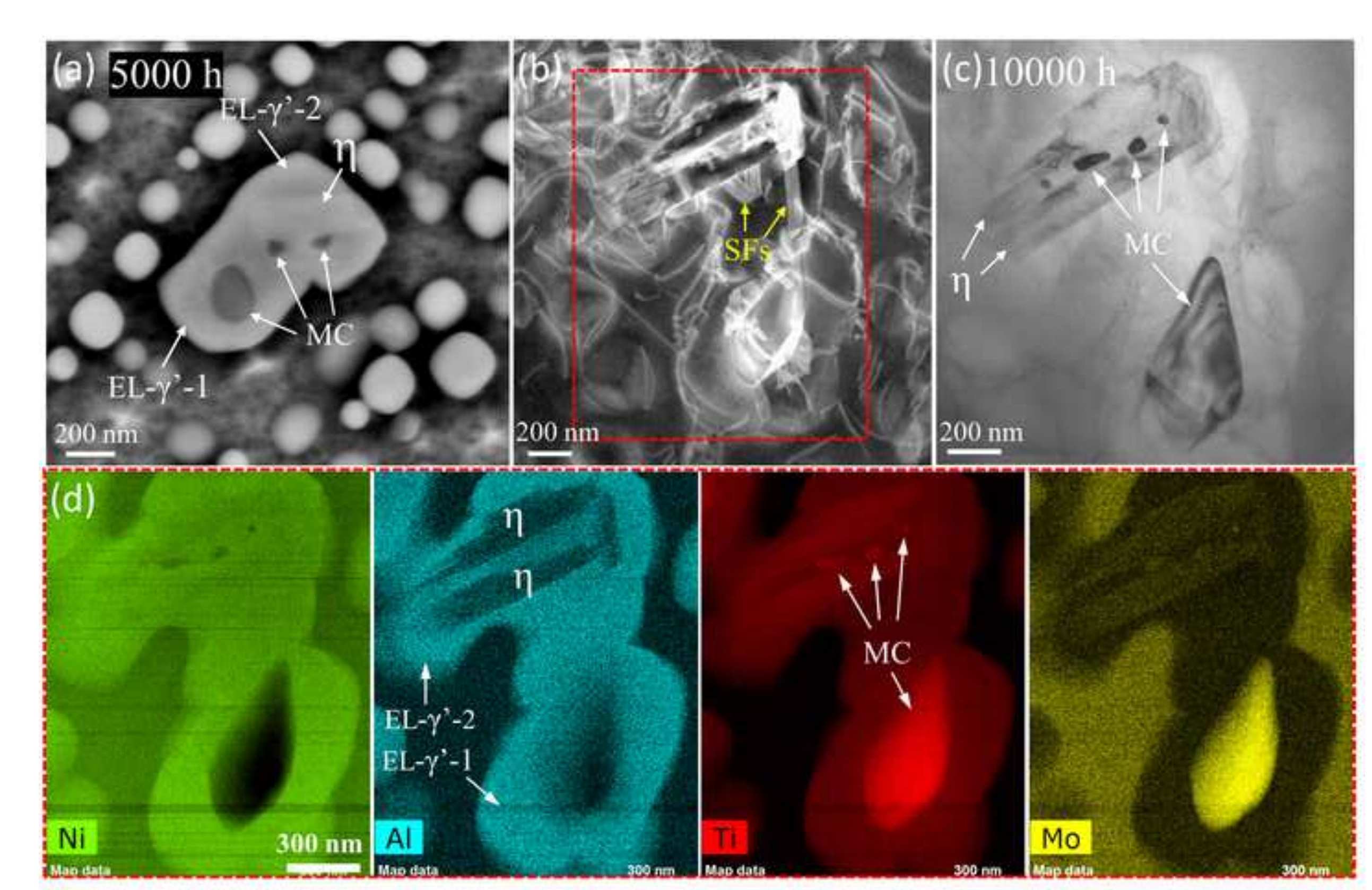




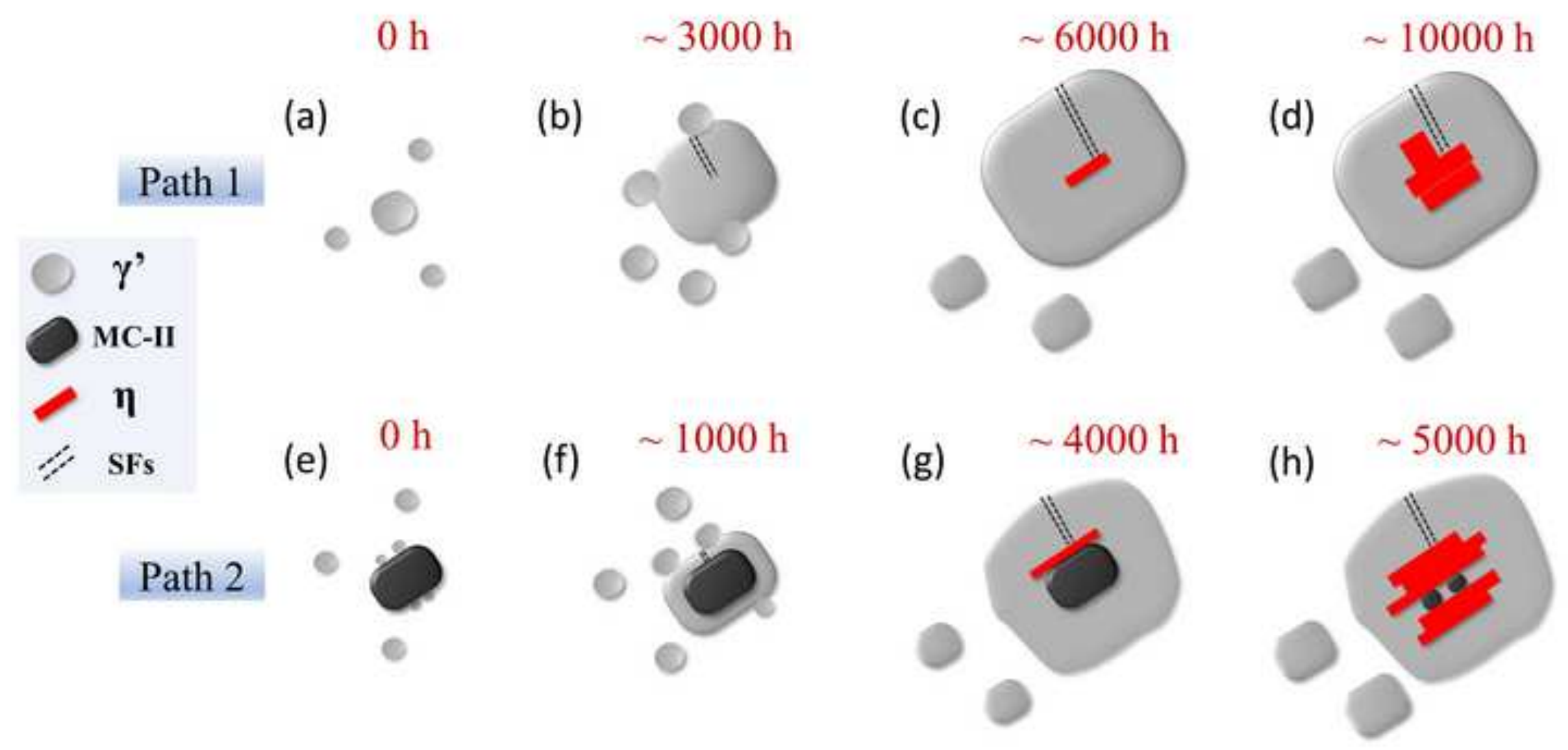



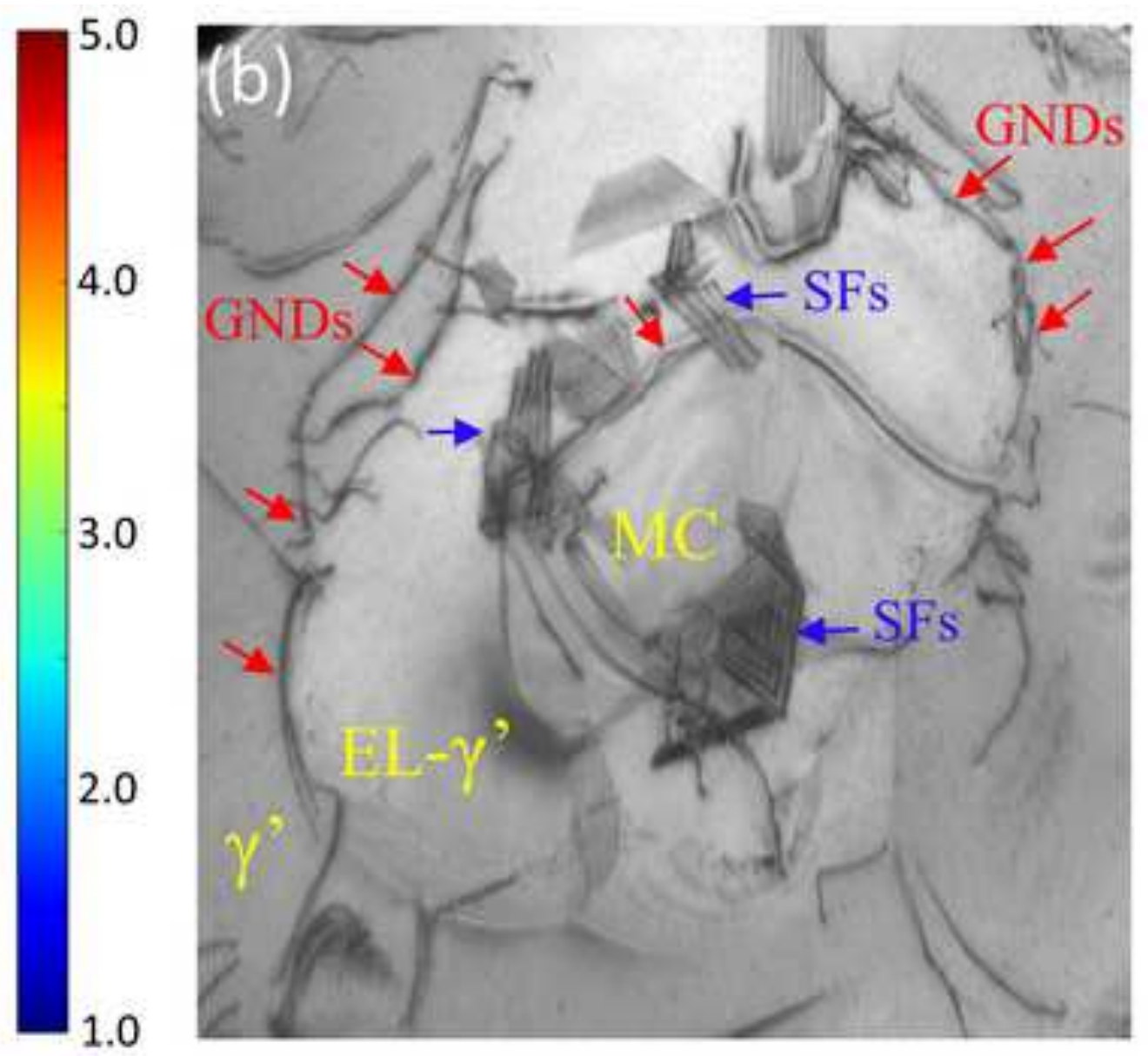

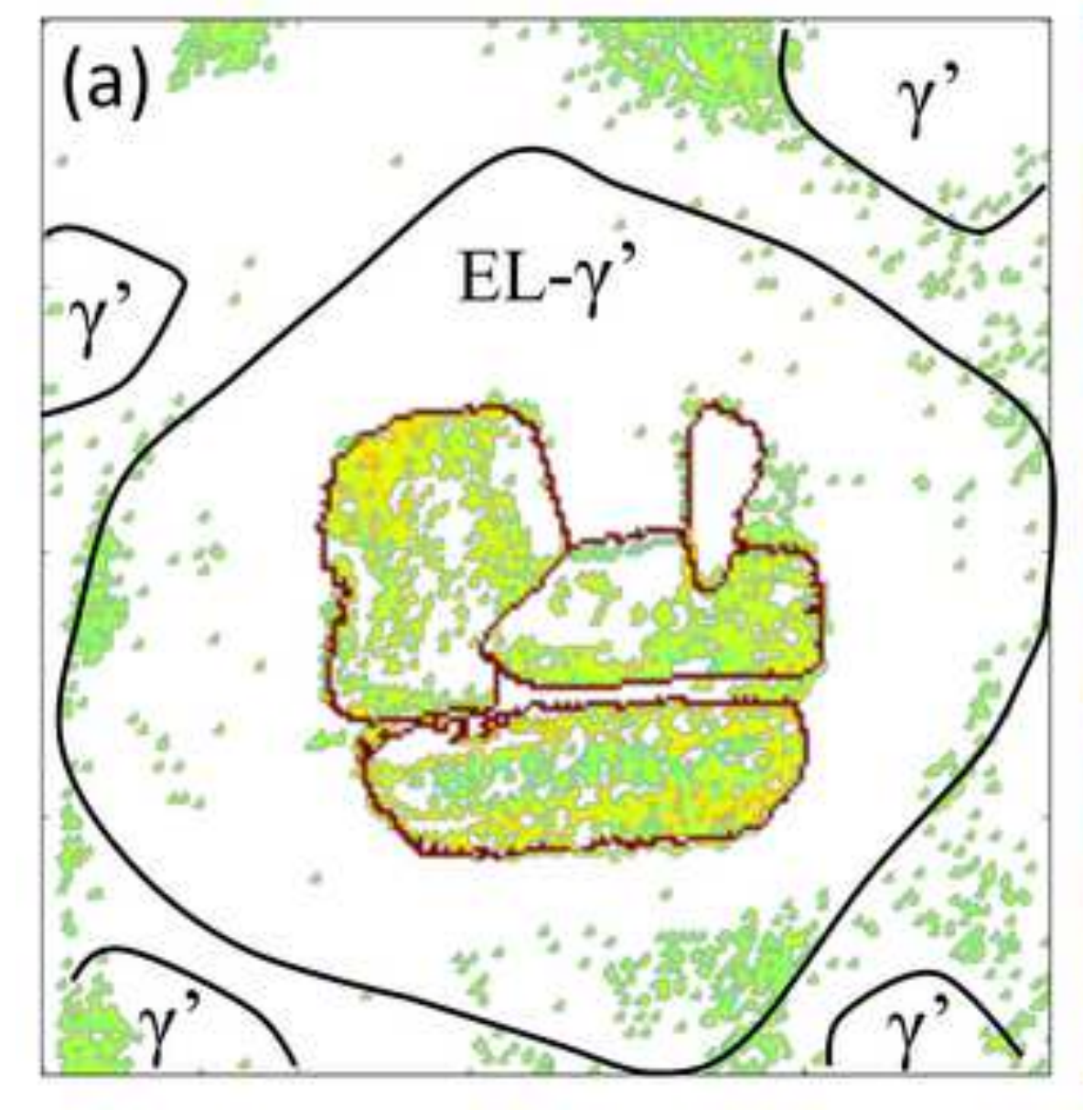

1.0 
Table 1. Average chemical composition (wt.\%) of large MC carbide (MC-I) and small MC carbide (MC-II).

\begin{tabular}{cccccccc}
\hline & Ni & Al & Ti & Mo & Co & Cr & C \\
\hline MC-I & $2.97 \pm 0.78$ & $0.37 \pm 0.26$ & $58.31 \pm 0.72$ & $33.49 \pm 0.78$ & $0.79 \pm 0.23$ & $1.65 \pm 0.27$ & $2.40 \pm 0.37$ \\
& & & & & & & \\
MC-II & $27.37 \pm 0.51$ & $0.25 \pm 0.12$ & $46.94 \pm 0.65$ & $14.96 \pm 0.45$ & $4.14 \pm 0.48$ & $4.05 \pm 0.35$ & $2.27 \pm 0.26$ \\
\hline
\end{tabular}


Table 2. Average chemical composition (wt.\%) of $\gamma$ matrix, normal size $\gamma^{\prime}$, EL- $\gamma$ ' and $\eta$ phase after $10000 \mathrm{~h}$ ageing.

\begin{tabular}{ccccccc}
\hline & Ni & Al & Ti & Mo & Co & Cr \\
\hline$\gamma$ & $53.10 \pm 0.25$ & $0.24 \pm 0.17$ & $0.74 \pm 0.11$ & $4.80 \pm 0.17$ & $15.10 \pm 0.19$ & $26.10 \pm 0.37$ \\
$\gamma$, & $78.70 \pm 0.51$ & $1.90 \pm 0.05$ & $10.70 \pm 0.22$ & $1.37 \pm 0.12$ & $4.10 \pm 0.17$ & $2.60 \pm 0.46$ \\
EL- $\gamma^{\prime}$ & $78.08 \pm 0.58$ & $2.03 \pm 0.16$ & $12.10 \pm 0.38$ & $1.15 \pm 0.18$ & $3.72 \pm 0.23$ & $2.22 \pm 0.57$ \\
$\eta$ & $74.18 \pm 0.44$ & $0.67 \pm 0.16$ & $17.04 \pm 0.34$ & $1.82 \pm 0.16$ & $4.46 \pm 0.24$ & $1.62 \pm 0.11$ \\
\hline
\end{tabular}


Supplementary Material
Click here to download S

Click here to download Supplementary Material: Supplementary Materials.docx

$x$

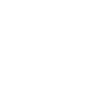

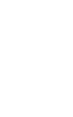

.

-

.

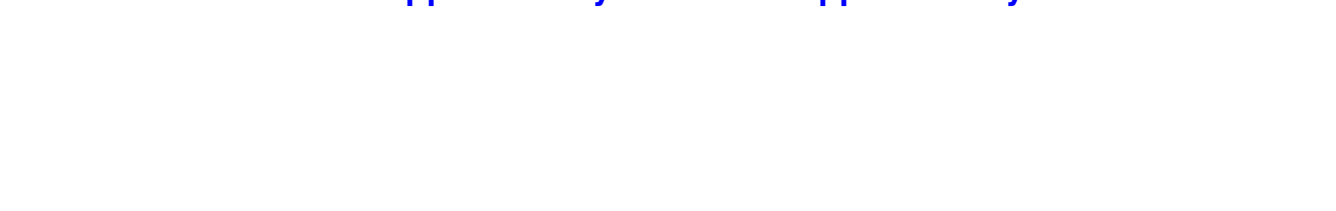




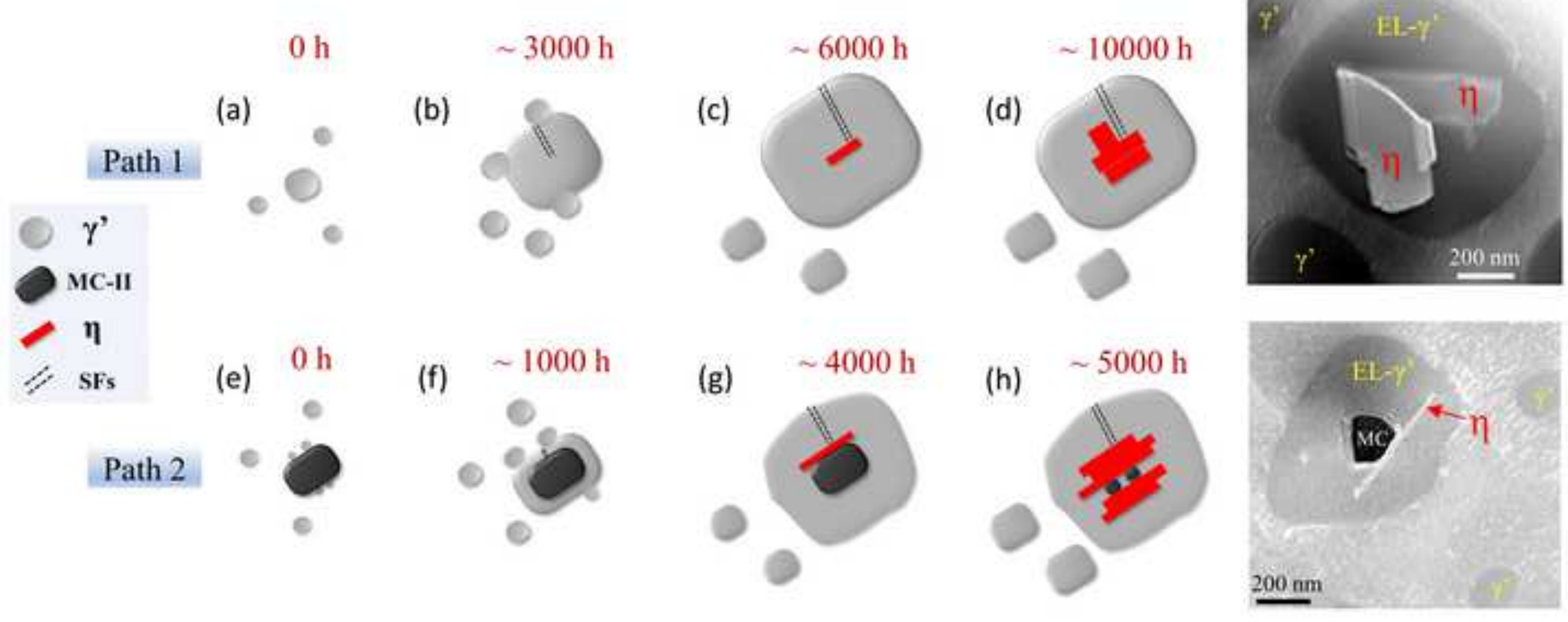




\section{${ }^{*}$ Declaration of Interest Statement}

\section{Declaration of interests}

$\bigotimes$ The authors declare that they have no known competing financial interests or personal relationships that could have appeared to influence the work reported in this paper.

$\square$ The authors declare the following financial interests/personal relationships which may be considered as potential competing interests:

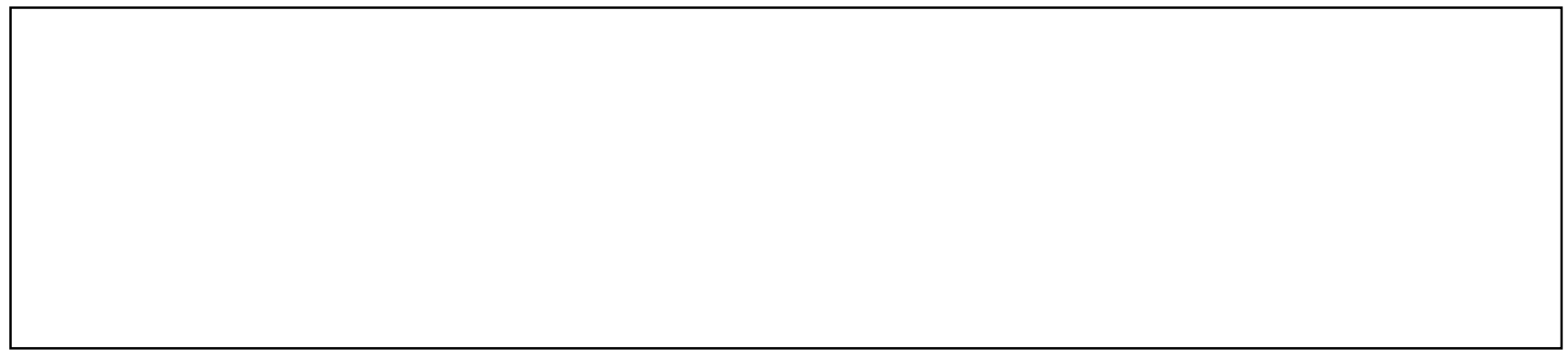

